\title{
SDU
}

\section{The size premium and intertemporal risk}

\author{
by
}

\section{Thiago de Oliveira Souza}

Discussion Papers on Business and Economics

No. $3 / 2016$

FURTHER INFORMATION

Department of Business and Economics

Faculty of Business and Social Sciences

University of Southern Denmark

Campusvej 55, DK-5230 Odense M

Denmark 


\title{
The size premium and intertemporal risk
}

\author{
Thiago de Oliveira Souza* \\ University of Southern Denmark
}

Current Version: June 15, 2016

First Draft: November 30, 2013

\begin{abstract}
The size premium only exists in states with good investment opportunities, when the aggregate (median) book-to-market is within the top 30\%, for example. The expected annual premium is around $9 \%$ in these states and insignificant otherwise. This fact is inconsistent with the unconditional version of the ICAPM, which predicts a negative size premium. The ICAPM does not condition down because of the time-varying risk premium, but there is almost no evidence that the conditional version of the ICAPM is consistent with the properties of the premium either. These results hold in each subperiod - before and after 1960 - between 1926 and 2014.
\end{abstract}

JEL classification: G11, G12, G14.

Keywords: Conditional, ICAPM, size premium, consistency, subsamples.

*Department of Business and Economics, University of Southern Denmark, Campusvej 55, 5230 Odense M, Denmark. Email: tsouza@sam.sdu.dk, phone number: +4565 5072 26. I would like to thank Stefano Giglio, John Cochrane, Paulo Maio, Lars Peter Hansen, Alexander Schandlbauer, Christian Riis Flor, Linda Sandris Larsen, Victor DeMiguel, Matías Braun, Jaime de Jesus, Marcelo Fernandes, Felipe Iachan, Charlie Cai, and the participants in the Arne Ryde Workshop in Financial Economics 2015, in the XIV Brazilian Finance Society Meetings, and in the World Finance Conference 2015. 


\section{Introduction}

There is some empirical evidence that the size premium is consistent with the intertemporal CAPM framework of Merton (1973): Maio and Santa-Clara (2012) report a positive correlation between the returns on the SMB portfolio of Fama and French (1993) and a state variable that is positively related with the future investment opportunities. So the positive excess returns on small stocks compared to the CAPM of Sharpe (1964) and Lintner (1965) would be consistent with their intertemporal risk exposures. On the other hand, we know since at least Pontiff and Schall (1998) that the aggregate book-to-market ratio (BM) positively predicts both the market and the small firms' excess returns. This result suggests (and I confirm) that the excess returns on small stocks covary negatively with the changes in the investment opportunities based on this state variable. But in this case the excess returns on small stocks should be negative in order to be consistent with their intertemporal risk exposures.

I explain this apparent contradiction by looking into the relation between the size premium, the investment opportunities, and the changes in the investment opportunities in more detail. First, I show that a size premium of around $9 \%$ per year arises exclusively in states of good investment opportunities: The premium is only significant when the aggregate (median) BM is among the top $10 \%$ to $30 \%$ in historical terms. This time-varying risk premium implies that the unconditional form of the ICAPM used in Maio and Santa-Clara (2012) to obtain the restrictions placed by the model on the risk premiums is not necessarily valid. Indeed, the ICAPM prediction of a positive size premium in Maio and Santa-Clara (2012) is almost entirely restricted to the states of the economy in which the size premium does not exist.

I obtain the relation between the state variables and the size premium using a procedure similar to the one applied in cross-section by Fama and French (1992), for example. Their standard procedure is to sort the stocks into portfolios based on a characteristic and analyze the differences in the mean returns on these portfolios. I add a third step to this procedure 
by sorting the years into groups according to their states (their median BM). ${ }^{1}$ I then examine the differences in the year-end average size premium among these states (groups of years).

The average year-end size premium tends to be significant only in states with aggregate/median BM in the top quantile(s) in historical terms. I divide the sample into 2, 3, 5,7 , or 10 quantiles. The size premium in each of the individual quantiles, except the top quantile(s), is almost always insignificant. Aggregating all the years together, except the ones in the top quantile, also yields insignificant size premiums. In addition, the significance of the size premium in the top quantile tends to increase with the median BM (i.e., with the number of quantiles used to split the data). I use U.S. data from 1926 to 2014 and individual subsamples before and after 1960 to confirm that the results are pervasive over time. For example, Pontiff and Schall (1998) report that the aggregate BM loses its forecasting power over the return on the market after 1960. I also use a double sort on size and CAPM betas to calculate the size premium obtaining the same qualitative results. Hence, the variation in the market risk premium does not explain the dynamics of the size premium over time.

Next, I investigate the consistency between the properties of the size premium and the ICAPM restrictions, first unconditionally and then conditioned on the BM state of the economy. I confirm that, unconditionally, the median BM has the properties of a state variable that is positively related to the future investment opportunities, as it forecasts improvements in the first and, to a lesser extent, the second moments of the market returns. But the unconditional covariance between the excess returns on small stocks and the changes in the BM tends to be negative. So within an unconditional ICAPM framework the SMB portfolio has intertemporal hedging properties and the size premium should be negative. This is inconsistent with the positive unconditional premium that we observe in the data.

Conditioning the analysis on the BM states clarifies the apparent contradiction between

\footnotetext{
${ }^{1}$ I explain the process in details in Section 3.1.1: I sort the years into groups/quantiles from high to low based on their median BM at the beginning of a yearly period starting in July of each year. I use the BM as the state variable to keep the results comparable with the ones in Pontiff and Schall (1998). But Souza (2016) shows that the results are similar using other return forecasters, such as the PE ratio of Shiller (2015), for example.
} 
the results above, which are expected considering Pontiff and Schall (1998), and the ones in Maio and Santa-Clara (2012). Maio and Santa-Clara (2012) construct the state variable SMB* in the spirit of the value spread of Campbell and Vuolteenaho (2004), showing that the variable is positively associated with the investment opportunities unconditionally. They argue that the return on the SMB portfolio is approximately equal to the innovations on SMB* by construction. Therefore, the return on the SMB portfolio would covary with the state variable (and with the investment opportunities). ${ }^{2}$ This would be consistent with the empirical observation of a positive size premium. In fact, I find even stronger support for the unconditional conclusions in Maio and Santa-Clara (2012) considering $S M B^{*}$ instead of the $\mathrm{BM}$ and report a stronger unconditional positive relation between their $S M B^{*}$ state variable and the investment opportunities. But the conditional results show that the significance of this relation is predominantly concentrated in the years when the size premium does not exist. Thus, the conditional form of the ICAPM (given the BM) predicts a positive premium exactly in the states where the premium does not exist (low and medium BM states). In the high BM states, which is when the size premium arises, the conditional ICAPM sometimes predicts a negative, positive, or no premium based on $S M B^{*}$ in different samples.

Finally, I investigate the consistency of the conditional predictions of the ICAPM considering the BM state variable. The conditional version of the ICAPM tends to predict a significantly negative size premium based on the BM state variable, particularly in the states where the premium does not exist (low and medium BM states). In general, the ICAPM prediction is unclear in the states where the premium exists: The covariances between the return on the SMB portfolio and the innovations on the BM state variable tend to become insignificant in these periods. In summary, I find almost no evidence that the small stocks are more exposed to intertemporal risk compared to the big stocks in a way that explains the size premium.

\footnotetext{
${ }^{2}$ In this paper I restrict my attention to the changes of the return on wealth over time. This is a common simplifying assumption in empirical tests of the ICAPM, but it ignores the changes in the macroeconomic conditions as in Boons (2016), for example.
} 
The first strand of the literature to which this paper belongs relates to confirming and detailing the existence and the pervasiveness of the stylized facts commonly used in empirical asset pricing. For instance, Fama and French (2012) and Asness, Moskowitz, and Pedersen (2013) report the pervasiveness of the value (Fama and French, 1992) and momentum effects (Jegadeesh and Titman, 1993) but find little evidence of the size premium. Among other consequences, the lack of evidence regarding the size premium and its risk explanations challenges the use of the factor models, such as the ones in Fama and French (1996) or Fama and French (2015), for routine risk adjustment in empirical work. It also raises doubts about the stylized facts, which theoretical work should aim to explain. Here, I show that the size premium is also pervasive, but it is a conditional effect instead of the unconditional premium documented in Banz (1981). This may justify the inclusion of the SMB portfolio in (conditional) factor models.

The paper also contributes to the discussion about the size premium as a compensation for risk. For example, Daniel and Titman (1997) and Davis, Fama, and French (2000) could not provide significant evidence to answer this question, which also Chordia, Goyal, and Shanken (2015) have addressed more recently. As discussed earlier, Maio and Santa-Clara (2012) in fact provide evidence that the size premium is a compensation for intertemporal risk in line with the ideas in Petkova (2006). But the results in Pontiff and Schall (1998) and the ones that I provide here confirm the lack of empirical support for the intertemporal risk explanation of the size premium.

Finally, this paper relates to the literature on empirical work on the ICAPM in conditional or unconditional forms as in Boons (2016), Koijen, Lustig, and Van Nieuwerburgh (2016), Maio (2013), Maio and Santa-Clara (2012), Bali (2008), or Ang, Hodrick, Xing, and Zhang (2006), for example. I show that the link between the variation in expected returns on the market over time and the variation in average returns in cross section that generates the size premium is not generally consistent with the ICAPM neither in conditional nor unconditional forms. The results also highlight the importance of conditioning information as in Hansen 
and Richard (1987) considering the fact that the expected returns vary over time (Cochrane, 2011).

The remainder of the paper is organized as follows: In Section 2, I briefly present the ICAPM model and its testable predictions. In Section 3, I present the empirical relation between the size premium and the BM state of the economy. In Section 4, I analyze the consistency between these facts and the ICAPM explanation for the size premium and also compare them with the results of Maio and Santa-Clara (2012). In Section 5, I summarize the paper.

\section{The ICAPM restrictions}

I briefly present a simplified continuous time version of the intertemporal CAPM of Merton (1973) based on a representative agent to obtain the restrictions placed by the model on the risk premiums. This is the version in Maio and Santa-Clara (2012), who also provide a more detailed explanation about its testable implications.

The return on each of the $N$ risky assets, $i$, follows a diffusion process:

$$
\frac{d S_{i}}{S_{i}}=\mu_{i}(z, t) d t+\sigma_{i}(z, t) d \xi_{i}, \quad i=1, \ldots, N
$$

where $S_{i}$ is the price of asset $i, d \xi_{i}$ is a standard Brownian motion, and $\sigma_{i j} d t$ is the covariance between assets $i$ and $j$.

Both the mean, $\mu_{i}$, and the volatility, $\sigma_{i}$, of the investment opportunities change with the state variable, $z$, which also follows a diffusion process:

$$
d z=a(z, t) d t+b(z, t) d \xi_{z}
$$

where $d \xi_{z}$ is a standard Brownian motion and $\sigma_{i z} d t$ is the covariance between asset $i$ and the state variable, $z$. 
For simplicity, the risk free asset has a constant instantaneous return, $r$ :

$$
\frac{d B}{B}=r d t
$$

So the agent chooses how much to consume, $C$, and the fraction of his wealth, $W$, allocated to each asset $i, \omega_{i}$. His wealth evolves as

$$
d W=\sum_{i=1}^{N} \omega_{i}\left(\mu_{i}-r\right) W d t+(r W-C) d t+\sum_{i=1}^{N} \omega_{i} W \sigma_{i} d \xi_{i},
$$

and the choices of $C$ and $\omega_{i}$ maximize his lifetime utility subject to the budget constraint $(4)$

$$
J(W, z, t)=\max _{C, \omega_{i}} E_{t}\left[\int_{s=t}^{\infty} U(C, s) d s\right],
$$

where $J(W, z, t)$ is the value function associated with the agent's optimization.

In this formulation the risk premium for asset $i$ is given by two risk components:

$$
\mu_{i}-r=\gamma \sigma_{i m}+\gamma_{z} \sigma_{i z} .
$$

The first component is related to market risk: The parameter of relative risk aversion, $\gamma \equiv-W J_{W W}(W, z, t) / J_{W}(W, z, t)$, multiplies $\sigma_{i m}$, the covariance between the return on asset $i$ and the market return. The second component is the intertemporal risk premium associated with the changes in the state variable $z$ : The risk price of the state variable, $\gamma_{z} \equiv-J_{W z}(W, z, t) / J_{W}(W, z, t)$, multiplies the covariance between the return on asset $i$ and the state variable, $\sigma_{i z} . J_{W}($.$) is the marginal value of wealth, J_{W W}($.$) is the change in the$ marginal value of wealth, and $J_{W z}($.$) is the cross-derivative of the marginal value of wealth$ with the change in the state variable. $J_{W z}($.$) expresses how the marginal value of wealth$ changes when the state variable changes. 
In discrete time, Eq. (6) is approximated by

$$
E_{t}\left(R_{i, t+1}\right)-R_{f, t+1}=\gamma \operatorname{cov}_{t}\left(R_{i, t+1}, R_{m, t+1}\right)+\gamma_{z} \operatorname{cov}_{t}\left(R_{i, t+1}, \Delta z_{t+1}\right)
$$

where $R_{i, t+1}$ is the return on asset $i, R_{f, t+1}$ is the risk free rate, $R_{m, t+1}$ is the return on the market, and $\Delta z_{t+1}$ is the innovation in the state variable.

When the second component in Eq. (7) is equal to zero, the pricing equation collapses to the CAPM. So the ability of the ICAPM to explain the CAPM anomalies relies exactly on this second term. But the ICAPM restricts the variables that can be added to the CAPM: The extra variables must be related to changes in state variables that forecast future investment opportunities and have the correct sign. For example, a state variable that forecasts positive aggregate returns,

$$
\operatorname{cov}_{t}\left(R_{m, t+2}, z_{t+1}\right)=\operatorname{cov}_{t}\left(E_{t+1}\left[R_{m, t+2}\right], z_{t+1}\right)=\operatorname{cov}_{t}\left(E_{t+1}\left[R_{m, t+2}\right], \Delta z_{t+1}\right)>0
$$

must be associated with a positive intertemporal risk price (and vice versa). ${ }^{3}$

On the other hand, a state variable that is positively correlated with the future volatility of the aggregate returns,

$$
\operatorname{cov}_{t}\left(R_{m, t+2}^{2}, z_{t+1}\right)=\operatorname{cov}_{t}\left(E_{t+1}\left[R_{m, t+2}^{2}\right], z_{t+1}\right)=\operatorname{cov}_{t}\left(E_{t+1}\left[R_{m, t+2}^{2}\right], \Delta z_{t+1}\right)>0
$$

will be associated with a negative risk price of intertemporal risk (and vice versa). ${ }^{4}$

\footnotetext{
${ }^{3}$ As Maio and Santa-Clara (2012) explain, this point is made clear if we assume an asset with returns positively correlated with the state variable:

$$
\operatorname{cov}_{t}\left(R_{i, t+1}, z_{t+1}\right)=\operatorname{cov}_{t}\left(R_{i, t+1}, \Delta z_{t+1}\right)>0
$$

In this case, the asset's return also covaries with the future aggregate returns:

$$
\operatorname{cov}_{t}\left(R_{i, t+1}, R_{m, t+2}\right)=\operatorname{cov}_{t}\left(R_{i, t+1}, E_{t+1}\left[R_{m, t+2}\right]\right)>0 .
$$

This asset pays off exactly when the investment opportunities are already good. So the ICAPM predicts a positive risk premium in equilibrium (compared to assets that do not covary with the investment opportunities).

${ }^{4}$ In this case, an asset with returns positively correlated with the state variable will have returns negatively
} 


\subsection{Conditioning down}

Under the assumption that the factor risk prices are constant, the law of iterated expectations gives the unconditional equivalent of Eq. (7):

$$
E\left(R_{i, t+1}\right)-R_{f, t+1}=\gamma \operatorname{cov}\left(R_{i, t+1}, R_{m, t+1}\right)+\gamma_{z} \operatorname{cov}\left(R_{i, t+1}, \Delta z_{t+1}\right) .
$$

This unconditional form, for example, is the version that Maio and Santa-Clara (2012) consider in their paper. But if the factor risk prices are time-varying, the model does not condition down in general and Eq. (13) does not necessarily hold. ${ }^{5}$

I base most of the empirical analysis of the paper on the conditional version of the ICAPM in Eq. (7). But the unconditional pricing Eq. (13) should still hold as an approximation when the factor risk prices are relatively constant. So I split the years in the sample according to their (BM) states, and analyze these groups individually. The risk prices should be similar among years with similar states, so Eq. (7) should condition down within those groups of years. $^{6}$

\section{The size premium and the state of the economy}

In this section I look into what happens to the returns on the SMB portfolio in the different states of the economy given by the median BM. The results hold in different periods, and they are robust to market risk: The conclusions are qualitatively the same obtaining correlated with the future market volatility:

$$
\operatorname{cov}_{t}\left(R_{i, t+1}, R_{m, t+2}^{2}\right)=\operatorname{cov}_{t}\left(R_{i, t+1}, E_{t+1}\left[R_{m, t+2}^{2}\right]\right)>0 .
$$

So the asset has (intertemporal) hedging properties because it pays off when the future market volatility increases (i.e., when the investment opportunities worsen). Therefore, in equilibrium this asset earns a negative risk premium compared to an asset that has no covariance with future volatility.

${ }^{5}$ Cochrane (2005) explains in chapter 8 a few other restrictive situations where the model in fact conditions down despite the time-varying risk premiums.

${ }^{6}$ Another alternative to deal with the time-varying risk prices is to try to explicitly model the factor risk prices as a function of the state variable - for example, including additional risk factors related to the state variable in the equation as in Jagannathan and Wang (1996), Lettau and Ludvigson (2001), or Maio (2013). 
the excess return on small stocks from double sorts on size and CAPM betas.

The data reduction obtained by the Fama/French portfolios is useful because it captures the covariances in returns that are supposedly related to the excess returns. From a theoretical perspective, this means that we only need to explain why there is a premium associated with a given portfolio, as stressed in Lewellen, Nagel, and Shanken (2010).

From an empirical perspective, it means that we can analyze the behavior of the Fama/French portfolios instead of analyzing each asset individually. More specifically, the size-related covariance in returns allows us to investigate if this common movement corresponds to a risk premium, restricting our attention to the SMB portfolio only. Another advantage is that the SMB portfolio is constructed as a double sort on value and size. This construction allows the SMB portfolio to be relatively free of value effects.

\subsection{Data and variables}

I use Kenneth French's data library to obtain the returns and the variables for the period between 1926 and 2014. All the returns and variables in year $t$ start in July. So the return on the SMB portfolio and the market premium are from July in $t$ to the end of June in $t+1$. The "begining of year" BM and SMB* in fact also correspond to July of year $t .{ }^{7} \mathrm{I}$ use annual data in the empirical analysis to avoid the short-term reversal in returns that generates the results in Vassalou and Xing (2004), for instance, as explained in Da and Gao (2010). This also guarantees that the composition of the portfolios does not change, given that a new portfolio is formed every June.

\footnotetext{
${ }^{7} \mathrm{BM}$ for (the end of June of) year $t$ is the book equity for the last fiscal year end in $t-1$ divided by the market value of equity in December of $t-1$. The last firms to publish their result will only have updated book equity for year $t-1$ in June of year $t$. Therefore, to avoid even a small forward-looking bias, I consider the BM to be known only in June of year $t$ even if the market value of equity is already 6 months delayed in this case. Between July in year $t$ to June in $t+1$ all the portfolios are the same. Accordingly, the returns that I calculate always correspond to the returns on those particular portfolios. The data can be found at http://mba.tuck.dartmouth.edu/pages/faculty/ken.french/data_library.html, and the full description of the variables can be found in Fama and French (1993).
} 


\subsubsection{Constructing the $B M_{t}$ state variable}

I use the median BM of all stocks in July to describe the state of the economy. Hence, I sort the years into quantiles according to this value (for instance, into high, medium, or low BM states). More specifically, I create the variable $B M_{t}$ :

$$
B M_{t} \equiv \ln \left(M_{B M, t}\right)-\overline{\ln \left(M_{B M}\right)}
$$

where $\ln \left(M_{B M, t}\right)$ is the natural logarithm of the median BM in year $t$, and $\overline{\ln \left(M_{B M}\right)}$ is the sample average of all values of $\ln \left(M_{B M, t}\right)$. Naturally, this transformation does not change the ranking of the years in terms of BM. But the logarithm transformation is useful when I use $B M_{t}$ in linear regressions later on. I subtract the full sample mean of the variable to easily compare the periods before and after 1960 with the original sample in terms of their $\mathrm{BM}$ values.

Fig. 1 shows a negative time trend in $B M_{t}$ that may reflect the long-term technological changes that result in less use of physical capital by the firms. But given that these changes may also reflect long-term time-varying risk premiums, I do not make any adjustments in the variable over time.

\section{[Place Fig. 1 about here]}

\subsubsection{Constructing $S M B^{*}$}

I follow the procedure described in Maio and Santa-Clara (2012) to construct their SMB* variable. The only difference is that I use yearly values instead of the monthly ones that they consider. In each period, $S M B^{*}$ is the difference between the market-to-book ratios of small and big stocks, using the six portfolios double sorted on size and BM that I obtain from Kenneth French's library:

$$
S M B^{*}=\frac{M B_{S L}+M B_{S M}+M B_{S H}}{3}-\frac{M B_{B L}+M B_{B M}+M B_{B H}}{3},
$$


where $M B_{S L}, M B_{S M}, M B_{S H}, M B_{B L}, M B_{B M}$, and $M B_{B H}$ are the market-to-book ratios of small-growth, small-middle BM, small-value, big-growth, big-middle BM, and big-value portfolios, respectively.

\subsubsection{Summary statistics}

Table 1 presents the preliminary evidence that the size premium only exists in states of good investment opportunities, as given by the median BM. The table displays the summary statistics for the market premium, the return on the SMB portfolio, and the state variable $B M_{t}$ from Eq. (14). I report the mean, standard deviation and the t-Mean (the ratio of mean to standard deviation) of these variables in each of the sample periods. The first

column reports the unconditional results (considering all the years in each sample). The next columns display the corresponding values of the variables in a breakdown of these years according to their states (low, medium, or high BM states).

\section{[Place Table 1 about here]}

The unconditional return on the SMB portfolio is two standard errors above zero in the full 1926-2014 period, but it is insignificant in both individual subperiods split in 1960 (Table 1). The average BM is significantly higher before 1960, and both the market premium and volatility are higher in that period, too.

The breakdown of the periods into states shows that the return on the SMB portfolio is never above the two standard error bound in the states with low or medium BM. On the contrary, the return on the SMB portfolio is largest and most significant in states of high BM. But even in the (relatively) high BM states, the return on the SMB portfolio is insignificant after 1960. This can be explained by the significantly low average BM in this period: The years with the largest BM in this period have an average BM of only 0.17 , which would correspond to a medium BM state before 1960, for example.

The market premium also tends to be largest and most significant in high BM states. 
This happens despite the market volatility tendency to increase in these states. The results in Table 1 are consistent with the evidence in Pontiff and Schall (1998) showing that the BM forecasts both the market and the excess return on small stocks. But the additional insight from Table 1 is that the size premium seems to exist exclusively in states of high BM (and good investment opportunities), as I confirm next.

\subsection{A closer look at the size premium in the BM states}

The results in Table 2 provide more detailed confirmation that the existence of the size premium is restricted to the high BM states. Here I vary the size of the groups of years with similar BM states. So we can analyze the significance of the size premium in each of these individual groups. This also clarifies the results in Table 1 about the period after 1960: The size premium arises exclusively in high BM years after 1960, just as it does before 1960. The difference is that after 1960 the premium only arises one fifth of the time, instead of one third of the time. One possible reason is the low average BM (and market premium) in this part of the sample.

In Table 2, I sort the years of each sample into 1 (i.e., all years), 2, 3, 5, 7, or $10 \mathrm{BM}$ quantiles. The table displays the mean and the t-Mean (the ratio of the mean to its standard error) of the return on the SMB portfolio. It describes each individual quantile in the first 10 columns on the left ("Bottom" to "Top"). The rightmost column, "Ex top", displays these estimates in a sample from which only the respective top quantile is removed. We can interpret the "Ex top" results as answering to what happens to the SMB portfolio in "ordinary" times when the investment opportunities are not "excellent". The number of ordinary years included in this calculation grows with the number of quantiles.

\section{[Place Table 2 about here]}

The significance of the return on the SMB portfolio is almost always restricted to the highest BM state(s). For example, the return on the SMB portfolio is never above the two 
standard error bound if we exclude the top BM quantile years from the sample. This happens in all the samples and for all numbers of quantiles considered (Table 2, "Ex top" column). In fact, the significance of the size premium tends to be restricted exclusively to the top quantile after 1960. But before 1960 the top two or three quantiles exhibit a significant size premium depending on the number of quantiles used to split the data.

Increasing the number of BM quantiles and looking at smaller groups of years highlights the non-linear relation between the size premium and the aggregate BM. The non-top individual groups of years tend to have insignificant size premiums. Both the significance and the point estimation of the size premium tend to increase substantially in the highest BM states only..$^{8}$

\subsubsection{Controlling for market risk}

The increase in the size premium in high BM states is not simply due to the increase in the market premium in those states, as it may seem from Table $1 .{ }^{9}$ To show that, I build a portfolio with a positive exposure to small stocks, a negative exposure to big stocks, and close to no exposure to market risk. I first obtain the returns on 25 portfolios double sorted into five groups of CAPM betas and size on Kenneth French's library. Next, I construct a portfolio with positive equal weights on the small stocks (the 10 portfolios with the smallest stocks) and negative equal weights on the big stocks (the 10 portfolios with the biggest stocks). The return on this portfolio, $R_{\text {Size,t }}$, is then given by

$$
R_{\text {Size }, t}=\frac{\sum_{s=1}^{2} \sum_{b=1}^{5} R_{\text {Size }_{s} \beta_{b}, t}-\sum_{s=4}^{5} \sum_{b=1}^{5} R_{\text {Size }_{s} \beta_{b}, t}}{20},
$$

\footnotetext{
${ }^{8}$ The same exercise using the $\mathrm{SMB}^{*}$ of Maio and Santa-Clara (2012) instead of $B M_{t}$ does not give equivalent results. In the next section I show that this may happen because the relation between the SMB* and the future investment opportunities is not linear.

9 The SMB portfolio is created as a long position on three portfolios containing small stocks and an offsetting short position on three portfolios of big stocks. Small stocks tend to have larger CAPM betas than big stocks so the SMB portfolio should carry positive market risk. In this case, the CAPM predicts exactly the behavior that I reported earlier: A larger size premium when the market returns are larger.
} 
where $R_{\text {Size }_{s} \beta_{b}, t}$ is the return on the portfolio formed by the stocks in the size quantile, $s$, and in the beta quantile, $b$. These returns are available from 1963 until 2014. Table 3 shows that the results are qualitatively the same as the ones considering the return on the SMB portfolio in Table 2. Table 3 reports exactly the same variables as Table 2 for the period 1963-2014.

\section{[Place Table 3 about here]}

\subsection{State variables and the investment set}

So far, I have been considering the BM as a state variable without precisely determining its properties. Within the ICAPM framework a variable must be related to changes in the marginal value of wealth from Eq. (5) to be a valid state variable. The marginal value of wealth changes, for example, when the future investment opportunities change. When there are positive shocks to the expected return on the market, or negative shocks to the expected market volatility, the marginal value of wealth decreases, meaning that the risk price, $\gamma_{z}$, in Eq. (6) is positive (and vice versa). And if both the expected return and volatility increase, for example, we may look at the net effect on the investment set by the changes in the conditional Sharpe ratios. Brennan and Xia (2006) and Nielsen and Vassalou (2006) explain the restrictions for this result to hold.

So here I investigate how the investment opportunities are related to the possible state variable, $z_{t}$. I analyze both $B M_{t}$ and the $S M B^{*}$ of Maio and Santa-Clara (2012) as the possible state variables.

\subsubsection{Forecasting the return on the market}

First, I check if the candidate state variable, $z_{t}$, forecasts the market premium. I run the standard predictive regressions for one and five years $(q=1$ or $q=5)$ for the excess return 
on the market:

$$
R_{m, t \rightarrow t+q}=\alpha_{R, q}+\beta_{R, q} z_{t}+\epsilon_{R, t \rightarrow t+q}
$$

where $R_{m, t \rightarrow t+q}$ is the annual compound excess return on the market during $q$ periods, from $t$ until $t+q$, and $\epsilon_{R, t \rightarrow t+q}$ is the error term. The positive relation between $z_{t}$ and the investment opportunities is given by the positive $\beta_{R, q}$.

\subsubsection{Forecasting the market volatility}

The investment set also changes when the market volatility changes, so these changes are of hedging concern to the investors, too. Therefore, I investigate how $z_{t}$ may forecast the market variance $(S V A R)$. I obtain these data from Amit Goyal's webpage, and the values correspond to the sum of squared daily returns on the S\&P Index used in Welch and Goyal (2008) and Maio and Santa-Clara (2012), for example. Again, I run the standard predictive regressions for one and five years $(q=1$ or $q=5)$ :

$$
S V A R_{m, t \rightarrow t+q}=\alpha_{S V A R, q}+\beta_{S V A R, q} z_{t}+\epsilon_{S V A R, t \rightarrow t+q},
$$

where $S V A R_{m, t \rightarrow t+q}$ is the cumulative sum of the realized variances over $q$ periods, from $t$ until $t+q$, and $\epsilon_{S V A R, t \rightarrow t+q}$ is the error term. A positive relation between $z_{t}$ and the investment opportunities would appear as a negative $\beta_{S V A R, q}$.

\subsubsection{The net effect on the conditional Sharpe ratios}

Finally, $z_{t}$ may be positively related to both the expected returns and expected volatility, for example. In this case, we can use a pseudo-conditional Sharpe ratio as a proxy to calculate the net change in the investment set. I obtain these values following the approach of Whitelaw (1994) and Maio and Santa-Clara (2012), who provide a more detailed explanation of its calculation.

This two-step procedure starts by obtaining the fitted expected returns, $\widehat{R}_{m, t \rightarrow t+q}$, using 
Eq. (17) and the fitted expected volatility, $\widehat{S V A R}_{m, t \rightarrow t+q}$, using Eq. (18) and constructing the pseudo-conditional Sharpe ratio:

$$
S R_{t \rightarrow t+q}=\frac{\widehat{R}_{m, t \rightarrow t+q}}{\sqrt{\widehat{S V A R}_{m, t \rightarrow t+q}}}=\frac{\hat{\alpha}_{R, q}+\hat{\beta}_{R, q} B M_{t}}{\sqrt{\hat{\alpha}_{S V A R, q}+\hat{\beta}_{S V A R, q} B M_{t}}}
$$

where $\hat{\alpha}_{R, q}$ and $\hat{\beta}_{R, q}$ are the estimated coefficients from the excess return predictive regression in Eq. (17), and $\hat{\alpha}_{S V A R, q}$ and $\hat{\beta}_{S V A R, q}$ are the estimated coefficients from the volatility forecast in Eq. (18).

Next, I calculate the average over time of the partial derivatives of the Sharpe ratio with respect to $z_{t}$ :

$$
\frac{\partial S \hat{R}_{t \rightarrow t+q}}{\partial z_{t}}=\hat{\beta}_{R, q} \widehat{S V A R}_{m, t \rightarrow t+q}^{-1 / 2}-\frac{1}{2} \widehat{S V A R}_{m, t \rightarrow t+q}^{-3 / 2} \hat{\beta}_{S V A R, q} \widehat{R}_{m, t \rightarrow t+q}
$$

\subsection{The $B M$ as a state variable}

Here, I provide evidence supporting the hypothesis that the median BM is a valid state variable positively associated with the investment opportunities. The relation is especially significant unconditionally, as we see from the first column in each panel in Table 4. But it tends to hold conditionally as well as we see in the other columns. The connection between $B M_{t}$ and the investment opportunities usually arises because $B M_{t}$ forecasts positive market returns, especially before 1960 and in the full sample.

\section{[Place Table 4 about here]}

In the full 1926-2014 sample, $B M_{t}$ unconditionally forecasts both positive expected market returns and (short-term) volatility. But the pseudo Sharpe ratio indicates a positive net effect on the investment opportunities even in the short run. Within each BM state, the predictive power of $B M_{t}$ becomes less clear. Most conditional coefficients are insignificant, with the most significant ones usually appearing in the high BM states. In high BM states $B M_{t}$ 
forecasts negative short-term investment opportunities and positive long-term investment opportunities because it forecasts positive short-term volatility.

Before 1960, $B M_{t}$ also tends to forecast positive investment opportunities both unconditionally and in each BM state. The difference is that before 1960 the conditional coefficients are more significant in the low BM states, especially the short-run coefficients. In the high BM states, $B M_{t}$ significantly forecasts higher volatility, so there is some evidence of a negative relation with the investment opportunities in those states. But the conditional Sharpe ratios in high BM states still indicate a positive relation with the the short-run investment opportunities, and no relation in the long run.

After 1960, $B M_{t}$ unconditionally forecasts significantly lower (long-term) market volatility but does not forecast the market return. ${ }^{10} B M_{t}$ is positively associated with the investment opportunities unconditionally, but the significance of the relation is restricted especially to the low BM states. Finally, in the high BM states after 1960 there is no significant relation with either the market return or the volatility.

\subsection{The $S M B^{*}$ forecasting properties conditioned on the BM state}

There is strong unconditional evidence of a positive relation between $S M B^{*}$ and the investment opportunities, as we see in Table 5. $S M B^{*}$ unconditionally forecasts both positive market returns (in every sample) and also lower volatility (before 1960 and in the full 19262014 sample). However, this evidence tends to be restricted to the low and medium BM states. In the high $\mathrm{BM}$ states the relation between $S M B^{*}$ and the investment set is either insignificant (pre 1960), negative (post 1960), or marginally positive (in the full sample).

\section{[Place Table 5 about here]}

The $S M B^{*}$ unconditionally forecasts positive market returns in every sample. But conditioning on the BM state of the economy, this relation is only significant in the low BM

\footnotetext{
${ }^{10}$ This is in line with the results in Pontiff and Schall (1998) reporting that after 1960 the aggregate BM loses its market return forecasting power.
} 
states in the full 1926-2014 sample. Considering the sample split in 1960, $S M B^{*}$ significantly forecasts the long- (5 years) and short-term (1 year) market returns in the low or the medium BM states, but never in the high BM states. In fact, after $1960 S M B^{*}$ seems to forecast negative market returns in the short and the long term in high BM years, even if the coefficients are not significant.

The $S M B^{*}$ also unconditionally forecasts negative market volatility in the full sample and before 1960. It also marginally forecasts lower volatility in high BM states in the full sample, but not in any of the individual subsamples before or after 1960. Before 1960, SMB* forecasts lower short- and long-term volatility in both low and medium BM states, but not in high BM states. After 1960, $S M B^{*}$ marginally forecasts higher volatility exclusively in high BM states.

So the net effect of $S M B^{*}$ on the investment opportunities tends to be positive if taken unconditionally, or in the low and medium BM states. But in the high BM states, an increase in $S M B^{*}$ tends to be associated with worse investment opportunities (after 1960), no significant relation (before 1960), or positive opportunities (in the full sample). So there is some evidence that the $S M B^{*}$ is a state variable: $S M B^{*}$ is positively related to the investment opportunities, but the relation changes in particular in the high BM states, exactly when the size premium arises.

\subsection{The $S M B^{*}$ as a state variable}

We can also explain the previous results considering the non-linearity of the relation between the $S M B^{*}$ and the investment opportunities. Conditioning the estimation on each $S M B^{*}$ tercile, we see that the positive unconditional relation between the investment opportunities and $S M B^{*}$ only holds for low or medium values of $S M B^{*}$. When $S M B^{*}$ is large (on the top tercile), the relation is either significantly negative (especially in the short term), or it is insignificant as we see in Table 6.

\section{[Place Table 6 about here]}


With respect to the market returns, $S M B^{*}$ unconditionally forecasts positive values in every sample, especially in the long term. But this relation is only positive and significant for low $S M B^{*}$ values. In high $S M B^{*}$ years, $S M B^{*}$ forecasts negative market returns in the short run in the full 1926-2014 sample and after 1960.

$S M B^{*}$ also forecasts lower market volatility unconditionally in the full 1926-2014 sample and before 1960. But again, this relation is restricted to low or medium $S M B^{*}$ values: $S M B^{*}$ does not forecast the market volatility in high $S M B^{*}$ years.

Consequently, the overall unconditional relation between $S M B^{*}$ and the investment opportunities is positive (columns "All" in each panel in Table 6). But for high $S M B^{*}$ values, the relation tends to be negative instead. This happens because the significance of the positive relation is usually restricted to low or medium values of $S M B^{*}$.

\section{The consistency of the size premium with the ICAPM}

In this section I analyze the consistency of the size premium with the theoretical restrictions placed by the ICAPM on the sign of the premium. I focus on $B M_{t}$ as a state variable, but I also consider the properties of $S M B^{*}$, especially conditioning on the BM states.

The key point of the analysis is that the ICAPM predicts a specific sign for the risk price, $\gamma_{z}$, in Eq. (7) once we stablish the relation between the state variable and the investment opportunities. For example, innovations on a state variable that forecasts positive investment opportunities should have a positive risk price for intertemporal (covariance) risk, $\gamma_{z}$. It is the second term in Eq. (7) that may explain the returns in excess of the CAPM predictions. So the sign of $\gamma_{z}$ taken together with the sign of the covariance between the return on the SMB portfolio and the innovations on the state variable,

$$
\operatorname{cov}_{t}\left(R_{S M B, t+1}, \Delta z_{t+1}\right),
$$

determine the sign of the premium predicted by the ICAPM in excess of the one predicted 
by the CAPM.

In the remainder of this section I consider jointly the sign of the estimated covariance in Eq. (21) and how the state variable relates with the investment opportunities. I determine this relation considering the signs of the $\operatorname{cov}_{t}\left(R_{m, t+2}, z_{t+1}\right)$ in Eq. (8), the $\operatorname{cov}_{t}\left(R_{m, t+2}^{2}, z_{t+1}\right)$ in Eq. (11), and the estimated derivative of the conditional Sharpe ratios with respect to the state variable in Eq. (20). I summarize these results in the tables in this section displaying a "plus" sign next to each of these values when their signs imply a positive intertemporal risk premium for the SMB portfolio, given the sign of the estimated covariance in Eq. (21). ${ }^{11} \mathrm{I}$ include the symbols regardless of the significance of the estimates.

The size premium is usually inconsistent with the ICAPM restrictions. First, because depending on the state variable considered, $B M_{t}$ or $S M B^{*}$, the unconditional covariances can imply either a significantly negative or positive size premium. Secondly, because conditioning the estimations on the state of the economy also gives conflicting results. For example, the estimations frequently predict a significantly positive or negative premium in states where the premium does not exist. And in the states where the premium exists, the estimations are frequently insignificant or imply a premium with the wrong sign.

\subsection{The ICAPM and the BM state variable}

There is almost no evidence that the intertemporal risk explains the size premium considering the $B M_{t}$ state variable. As we see in the first column of Table $7, B M_{t}$ is positively related to the investment opportunities unconditionally. So the risk price for intertemporal (covariance) risk $\gamma_{z}$ in Eq. (7) is positive. But the unconditional version of the ICAPM wrongly predicts a negative size premium because of the (marginally significant) negative covariances of the return on the SMB portfolio with the changes in $B M_{t}$ in the full 1926-2014

\footnotetext{
${ }^{11}$ For example, the estimated covariance between the return on the SMB portfolio and the innovations on the state variable in Eq. (21) may be positive. If the estimated covariance between the state variable and the future market returns, $\operatorname{cov}_{t}\left(R_{m, t+2}, z_{t+1}\right)$ in Eq. (8), are also positive then the premium on the SMB portfolio should be positive considering this specific result. So I write a plus symbol next to $\operatorname{cov}_{t}\left(R_{m, t+2}, z_{t+1}\right)$ in the table. I include a plus symbol next to this specific covariance even when the other covariances imply a negative premium.
} 
sample and before 1960. After 1960, the ICAPM would predict zero excess return over the CAPM given the insignificant covariance between the return on the SMB portfolio and the innovations in $B M_{t}$. This prediction is, again, inconsistent with the data.

\section{[Place Table 7 about here]}

Conditioned on the BM state of the economy, the covariance of the return on the SMB portfolio with the innovations in the state variable in Eq. (21) is negative and at least marginally significant in the low and medium BM states in every sample except in the low BM states after 1960 (Table 7). Given that $B M_{t}$ also tends to be positively related to the investment opportunities in these states, the risk price $\gamma_{z}$ in Eq. (7) is positive as well. So the ICAPM predicts a significantly negative size premium in low BM states (in the full sample and before 1960) and a marginally significant and negative size premium in medium BM states before 1960. The ICAPM also predicts a significantly positive size premium in medium BM states after 1960. But none of these predictions are consistent with the insignificant premium that we observe in low and medium BM states.

In the high BM states, the covariance with the innovations in the state variable in Eq. (21) becomes insignificant in every sample, so the ICAPM predicts no size premium. Again, this is inconsistent with the significant size premium that arises in the high BM states. If we assume that the negative covariance in Eq. (21) that we observe in the other states also holds in the high BM states, the implications are still not conclusive. For example, in the full sample the ICAPM would predict a positive premium considering the negative relation between $B M_{t}$ and the short-term investment opportunities. But the relation between $B M_{t}$ and the long-term investment opportunities is positive implying a negative size premium instead. So the sign of the risk price $\gamma_{z}$ would still be unclear in this case. 


\subsection{The $S M B^{*}$ as a possible state variable}

\subsubsection{The $S M B^{*}$ in the different BM states}

Different from the previous results using $B M_{t}$ as a state variable, there is unconditional evidence supporting the intertemporal risk explanation of the size premium considering $S M B^{*}$ as a state variable. But after conditioning on the BM state of the economy the evidence usually disappears. This happens because the positive relation between $S M B^{*}$ and the investment opportunities tends to be restricted to the low and medium BM states as we saw in details in Table 5. These are the BM states where the size premium is insignificant.

Consistent with the data, the unconditional ICAPM predicts a positive size premium in the full 1926-2014 sample and after 1960, as we see in Table 8. The unconditional results in the first column of Table 8 show that the covariance risk price with the innovations in $S M B^{*}, \gamma_{z}$ in Eq. (7), is positive in the full sample and in each subsample. The covariance of the innovations in $S M B^{*}$ and the return on the SMB portfolio in Eq. (21) is significantly positive in the 1926-2014 sample and before 1960. Hence, the ICAPM predicts a positive size premium consistent with the data in those samples. Before 1960 the unconditional covariance in Eq. (21) is insignificant, so the ICAPM predicts no size premium, which is again in line with the data.

\section{[Place Table 8 about here]}

Conditionally, the risk price $\gamma_{z}$ in Eq. (7) is significantly positive in high BM states and especially in low BM states in the full 1926-2014 sample, as we see in Table 8. Therefore, the positive covariance of the return on the SMB portfolio and the innovations in $S M B^{*}$ in Eq. (21) implies a positive size premium in high BM states and especially in low BM states according to the ICAPM. But while this prediction is consistent with the positive size premium in high BM states, it is inconsistent with the insignificant size premium in low BM states. Again in line with the data, the ICAPM predicts no size premium in medium BM states because the (apparently positive) relation between $S M B^{*}$ and the future investment 
opportunities is not significant.

Before 1960 the ICAPM predicts no size premium in any of the BM states, as we see in Table 8. The relation between $S M B^{*}$ and the investment opportunities is insignificant in the high BM states. Accordingly, the risk price, $\gamma_{z}$, in Eq. (7) is zero and the ICAPM predicts no size premium in the high BM states. On the other hand, the relation between $S M B^{*}$ and the investment opportunities is significantly positive in low and medium BM states, so the risk price $\gamma_{z}$ in Eq. (7) is positive. But the insignificant covariance between the return on the SMB portfolio and the innovations in $S M B^{*}$ in low and medium BM states implies that the size premium should be zero according to the ICAPM. The insignificant size premium is consistent with the ICAPM in the low and medium BM states, but the ICAPM cannot explain the significantly positive size premium in the high BM states.

After 1960, the ICAPM predicts no size premium in low and medium BM states (consistent with the data) and a negative premium in high BM states (not consistent with the data). The relation between $S M B^{*}$ and the investment opportunities in low, medium, and high BM states is, respectively, insignificant, positive, and negative. So the risk price $\gamma_{z}$ in Eq. (7) is, respectively, zero, positive, and negative in low, medium, and high BM states. Given $\gamma_{z}=0$, the ICAPM predicts no size premium in low BM states. The insignificant covariance between the return on the SMB portfolio and the innovations in $S M B^{*}$ in medium BM states also implies no size premium in medium BM states according to the ICAPM. And the positive covariance between the return on the SMB portfolio and the innovations in $S M B^{*}$ in high $\mathrm{BM}$ states implies a negative size premium. Again, the insignificant size premium is consistent with the ICAPM in the low and medium BM states. But the ICAPM cannot explain the insignificant size premium in high BM states, especially considering its positive point estimation. 


\subsubsection{The $S M B^{*}$ as a state variable conditioning on the $S M B^{*}$ states}

The relation between the size premium and $S M B^{*}$ is not similar to the relation between the size premium and $B M_{t}$. So conditioning the analysis on the $S M B^{*}$ should not be as informative as conditioning on the $B M_{t}$. But we can still investigate the properties of $S M B^{*}$ as a state variable conditioning the analysis on the low, medium, and high $S M B^{*}$ years. In Table 9 we see the same unconditional results that were presented in the previous section: Consistent with the data, the ICAPM predicts a positive size premium in the full 1926-2014 sample and after 1960, and no premium before 1960. The difference is in the conditional results.

\section{[Place Table 9 about here]}

The conditional results in the full 1926-2014 sample show that the covariance between the $S M B^{*}$ and the investment opportunities is, respectively, positive, marginally positive, and negative in low, medium, and high $S M B^{*}$ years. Accordingly, the risk price $\gamma_{z}$ in Eq. (7) is positive in low and medium $S M B^{*}$ years and negative in high $S M B^{*}$ years. In addition,

the covariance between the return on the SMB portfolio and the innovations in $S M B^{*}$ is positive in all periods. Thus, the ICAPM predicts a positive size premium in medium $S M B^{*}$ years that is consistent with the data. But the ICAPM also predicts a positive size premium in low $S M B^{*}$ years and a negative premium in high $S M B^{*}$ years that are not consistent with the data.

Before 1960, the covariance between the return on the SMB portfolio and the innovations in $S M B^{*}$ is insignificant in low and medium $S M B^{*}$ years. So consistent with the data, the ICAPM predicts no size premium in these periods. This happens even if the risk price $\gamma_{z}$ in Eq. (7) is positive in low $S M B^{*}$ years given the positive covariance between $S M B^{*}$ and the investment opportunities in these years. But in high $S M B^{*}$ years the risk price $\gamma_{z}$ in Eq. (7) is zero, so again the ICAPM predicts no size premium instead of the large premium that we observe in these periods. 
After 1960, the covariance between the return on the SMB portfolio and the innovations in $S M B^{*}$ is positive in all periods. Hence, the size premium predicted by the ICAPM has the same sign as the risk price $\gamma_{z}$ in Eq. (7), given by the relation between $S M B^{*}$ and the investment opportunities. The relation between $S M B^{*}$ and the investment opportunities is, respectively, positive, insignificant, and negative in low, medium, and high $S M B^{*}$ years. Therefore, the insignificant size premium in medium $S M B^{*}$ years is consistent with the ICAPM predictions. But the insignificant premiums in low and high $S M B^{*}$ years are not consistent with the ICAPM.

\section{Summary}

We learn two broad new facts from this paper: First, the existence of the size premium is restricted to the states with good investment opportunities. Second, the intertemporal risk exposures of small stocks do not in general explain the existence of the size premium within an ICAPM framework.

The paper provides a more detailed description of the size premium, contributing to the original documentation in Banz (1981). I show that the size premium is pervasive but conditional. This conditional premium is in fact around three times larger than previously estimated, and it is approximately $9 \%$ per year. But there is no evidence that the premium exists around $70 \%$ to $90 \%$ of the time. This explains the lack of evidence about the size premium in several studies and suggests the inclusion of a conditional size factor in empirical asset pricing models.

I also show that the ICAPM explanation for the size premium has little empirical support both in its unconditional and, especially, conditional forms. The unconditional results are mixed: The results based on the $S M B^{*}$ variable of Maio and Santa-Clara (2012) in fact imply that the unconditional version of the ICAPM is consistent with the positive size premium. But considering the $B M_{t}$ of Pontiff and Schall (1998) as the state variable implies that 
even the unconditional version of the ICAPM is inconsistent with the size premium: The ICAPM predicts a negative unconditional premium in this case. The conditional version of the ICAPM is also usually inconsistent with the size premium because it often predicts a premium with a sign different from the one observed in the data. This conditional analysis is crucial because the risk premiums are time varying and the ICAPM does not condition down. 


\section{References}

Ang, A., Hodrick, R. J., Xing, Y., Zhang, X., 2006. The cross-section of volatility and expected returns. The Journal of Finance 61, 259-299.

Asness, C. S., Moskowitz, T. J., Pedersen, L. H., 2013. Value and momentum everywhere. The Journal of Finance 68, 929-985.

Bali, T. G., 2008. The intertemporal relation between expected returns and risk. Journal of Financial Economics 87, 101-131.

Banz, R. W., 1981. The relationship between return and market value of common stocks. Journal of Financial Economics 9, 3-18.

Boons, M., 2016. State variables, macroeconomic activity, and the cross section of individual stocks. Journal of Financial Economics 119, 489 - 511.

Brennan, M. J., Xia, Y., 2006. Risk and valuation under an intertemporal capital asset pricing model. The Journal of Business 79, 1-36.

Campbell, J. Y., Vuolteenaho, T., 2004. Bad beta, good beta. American Economic Review 94, 1249-1275.

Chordia, T., Goyal, A., Shanken, J. A., 2015. Cross-sectional asset pricing with individual stocks: betas versus characteristics. Available at SSRN 2549578 .

Cochrane, J. H., 2005. Asset Pricing, revised edition. Princeton University Press, Princeton.

Cochrane, J. H., 2011. Presidential Address: Discount rates. The Journal of Finance 66, $1047-1108$.

Da, Z., Gao, P., 2010. Clientele change, liquidity shock, and the return on financially distressed stocks. Journal of Financial and Quantitative Analysis 45, 27-48. 
Daniel, K., Titman, S., 1997. Evidence on the characteristics of cross sectional variation in stock returns. The Journal of Finance 52, 1-33.

Davis, J. L., Fama, E. F., French, K. R., 2000. Characteristics, covariances, and average returns: 1929 to 1997. The Journal of Finance 55, 389-406.

Fama, E. F., French, K. R., 1992. The cross-section of expected stock returns. The Journal of Finance 47, 427-465.

Fama, E. F., French, K. R., 1993. Common risk factors in the returns on stocks and bonds. Journal of Financial Economics 33, 3-56.

Fama, E. F., French, K. R., 1996. Multifactor explanations of asset pricing anomalies. The Journal of Finance 51, 55-84.

Fama, E. F., French, K. R., 2012. Size, value, and momentum in international stock returns. Journal of Financial Economics 105, 457-472.

Fama, E. F., French, K. R., 2015. A five-factor asset pricing model. Journal of Financial Economics 116, 1-22.

Hansen, L. P., Richard, S. F., 1987. The role of conditioning information in deducing testable restrictions implied by dynamic asset pricing models. Econometrica 55, 587-613.

Jagannathan, R., Wang, Z., 1996. The conditional CAPM and the cross-section of expected returns. The Journal of Finance 51, 3-53.

Jegadeesh, N., Titman, S., 1993. Returns to buying winners and selling losers: Implications for stock market efficiency. The Journal of Finance 48, 65-91.

Koijen, R. S., Lustig, H., Van Nieuwerburgh, S., 2016. The cross-section and time-series of stock and bond returns. Tech. rep. 
Lettau, M., Ludvigson, S., 2001. Resurrecting the (C)CAPM: A cross-sectional test when risk premia are time-varying. Journal of Political Economy 109, 1238-1287.

Lewellen, J., Nagel, S., Shanken, J., 2010. A skeptical appraisal of asset pricing tests. Journal of Financial Economics 96, 175-194.

Lintner, J., 1965. The valuation of risk assets and the selection of risky investments in stock portfolios and capital budgets. The Review of Economics and Statistics 47, 13-37.

Maio, P., 2013. Intertemporal CAPM with conditioning variables. Management Science 59, $122-141$.

Maio, P., Santa-Clara, P., 2012. Multifactor models and their consistency with the ICAPM. Journal of Financial Economics 106, 586-613.

Merton, R. C., 1973. An intertemporal capital asset pricing model. Econometrica 41, 867887.

Nielsen, L. T., Vassalou, M., 2006. The instantaneous capital market line. Economic Theory $28,651-664$.

Petkova, R., 2006. Do the Fama-French factors proxy for innovations in predictive variables? The Journal of Finance 61, 581-612.

Pontiff, J., Schall, L. D., 1998. Book-to-market ratios as predictors of market returns. Journal of Financial Economics 49, 141-160.

Sharpe, W. F., 1964. Capital asset prices: A theory of market equilibrium under conditions of risk. The Journal of Finance 19, 425-442.

Shiller, R. J., 2015. Irrational exuberance. Princeton University Press.

Souza, T. d. O., 2016. The CAPM misspecification and the size-related anomalies. Unpublished working paper. University of Southern Denmark . 
Vassalou, M., Xing, Y., 2004. Default risk in equity returns. The Journal of Finance 59, $831-868$.

Welch, I., Goyal, A., 2008. A comprehensive look at the empirical performance of equity premium prediction. Review of Financial Studies 21, 1455-1508.

Whitelaw, R. F., 1994. Time variations and covariations in the expectation and volatility of stock market returns. The Journal of Finance 49, 515-541. 


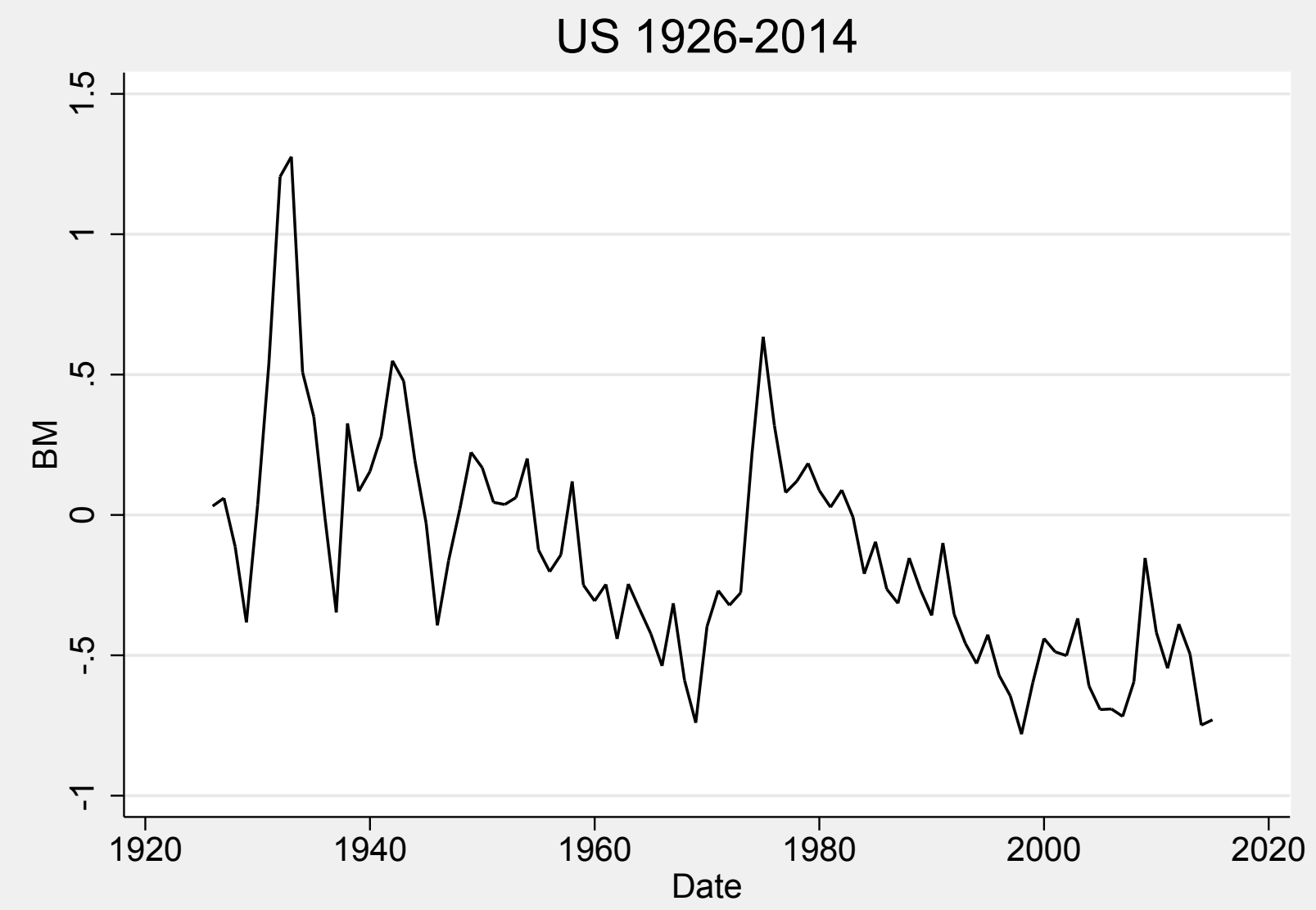

Fig. 1. Book-to-market time series. The panel plots the time series of $B M_{t}$ between 1926-2014. I use these values to classify the states of the economy according to their "good" or "bad" investment opportunities. 


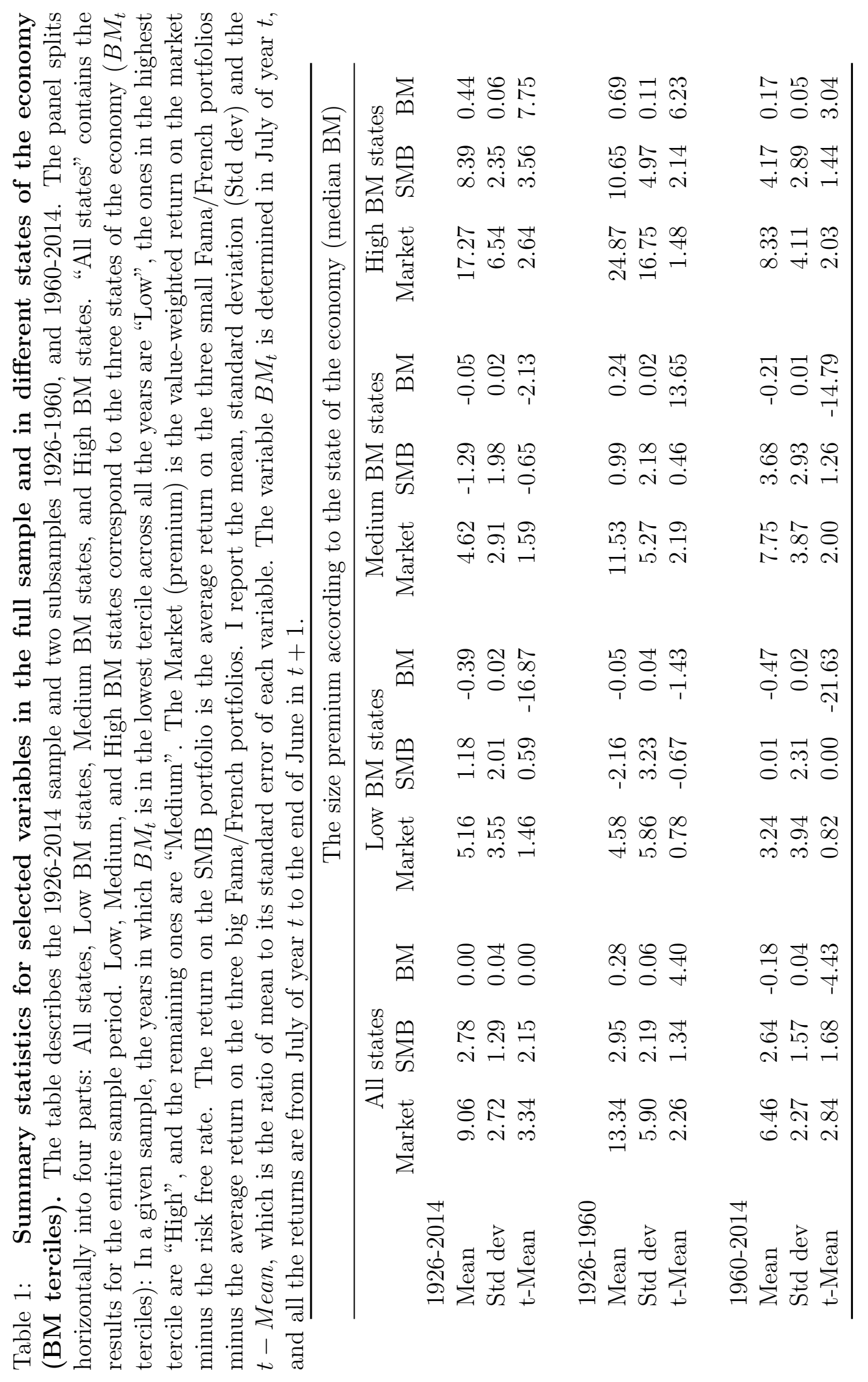


Table 2: Returns on the SMB portfolio when I vary the number of BM quantiles to group the years with similar states: Mean and $(t-M e a n)$, the ratio of the mean return to its standard error, of the return on the SMB portfolio in 1926-2014 and subsamples 1926-1960 and 1960-2014.

I split each sample into (1), 2, 3, 5, 7, or 10 quantiles based on the $B M_{t}$ state variable and report the results for all of these groups of years. Each row corresponds to a given number of quantiles. The number of quantiles is in the first column: All years (i.e., the whole sample), 2, 3, 5, 7, or 10. The number of years in each group is in brackets. The next 10 columns contain the results for each respective group of years, from 1 to 10, depending on the number of quantiles considered. The last column, "Ex top", displays the results considering all the years except the ones in the highest BM quantile. The variable $B M_{t}$ is determined in July of year $t$, and all the returns are from July of year $t$ to the end of June in $t+1$.

\begin{tabular}{|c|c|c|c|c|c|c|c|c|c|c|c|}
\hline \multicolumn{12}{|c|}{ Return on the SMB portfolio in each state (BM quantile) } \\
\hline & Bottom & 2 & 3 & 4 & 5 & 6 & 7 & 8 & 9 & Top & Ex top \\
\hline \multicolumn{12}{|l|}{$1926-2014$} \\
\hline All (89 obs.) & $\begin{array}{r}2.78 \\
(2.15)\end{array}$ & & & & & & & & & & \\
\hline \multirow[t]{2}{*}{$2(44)$} & 0.09 & 5.41 & & & & & & & & & 0.09 \\
\hline & $(0.05)$ & $(2.96)$ & & & & & & & & & $(0.05)$ \\
\hline \multirow[t]{2}{*}{$3(29)$} & 1.18 & -1.29 & 8.39 & & & & & & & & -0.08 \\
\hline & $(0.59)$ & $(-0.65)$ & $(3.56)$ & & & & & & & & $(-0.05)$ \\
\hline \multirow[t]{2}{*}{$5(18)$} & -0.76 & 2.42 & -2.72 & 5.45 & 9.03 & & & & & & 1.19 \\
\hline & $(-0.33)$ & $(0.73)$ & $(-1.63)$ & $(1.92)$ & $(2.87)$ & & & & & & $(0.88)$ \\
\hline \multirow[t]{2}{*}{$7(13)$} & -2.17 & 5.98 & -1.16 & -2.43 & -1.44 & 9.51 & 11.44 & & & & 1.43 \\
\hline & $(-0.77)$ & $(2.42)$ & $(-0.27)$ & $(-1.37)$ & $(-0.59)$ & $(3.07)$ & $(2.58)$ & & & & $(1.13)$ \\
\hline \multirow[t]{2}{*}{$10(9)$} & -5.20 & 3.18 & 5.63 & -0.48 & -3.63 & -1.91 & 0.41 & 10.48 & 5.22 & 12.83 & 1.65 \\
\hline & $(-2.1)$ & $(0.95)$ & $(1.53)$ & $(-0.09)$ & $(-1.51)$ & $(-0.79)$ & $(0.14)$ & $(2.36)$ & $(2.45)$ & $(2.2)$ & $(1.34)$ \\
\hline \multicolumn{12}{|l|}{$1926-1960$} \\
\hline All (35 obs.) & $\begin{array}{r}2.95 \\
(1.34)\end{array}$ & & & & & & & & & & \\
\hline \multirow[t]{2}{*}{$2(17)$} & $\begin{array}{l}-2.37 \\
-2.37\end{array}$ & 8.57 & & & & & & & & & -2.37 \\
\hline & $(-1.07)$ & $(2.5)$ & & & & & & & & & $(-1.07)$ \\
\hline \multirow[t]{2}{*}{$3(12)$} & -2.16 & 0.99 & 10.65 & & & & & & & & -0.58 \\
\hline & $(-0.67)$ & $(0.46)$ & $(2.14)$ & & & & & & & & $(-0.3)$ \\
\hline \multirow[t]{2}{*}{$5(7)$} & -5.21 & -0.30 & 1.21 & 2.65 & 16.37 & & & & & & -0.41 \\
\hline & $(-1.53)$ & $(-0.07)$ & $(0.43)$ & $(1.22)$ & $(2.35)$ & & & & & & $(-0.25)$ \\
\hline \multirow[t]{2}{*}{$7(5)$} & -7.24 & -3.57 & 2.57 & 0.82 & 3.71 & 6.30 & 18.03 & & & & 0.43 \\
\hline & $(-1.61)$ & $(-0.96)$ & $(0.53)$ & $(0.22)$ & (1.17) & (2.35) & $(1.81)$ & & & & $(0.26)$ \\
\hline \multirow[t]{2}{*}{$10(4)$} & -10.20 & 1.46 & -0.01 & -0.70 & -1.01 & 4.18 & 2.88 & 2.35 & 7.64 & 28.01 & 0.60 \\
\hline & $(-2.33)$ & $(0.74)$ & $(0)$ & $(-0.12)$ & $(-0.41)$ & $(0.68)$ & $(0.73)$ & $(2.03)$ & $(1.74)$ & $(2.07)$ & $(0.37)$ \\
\hline \multicolumn{12}{|l|}{$1960-2014$} \\
\hline \multirow[t]{2}{*}{ All (55 obs.) } & 2.64 & & & & & & & & & & \\
\hline & (1.68) & & & & & & & & & & \\
\hline \multirow[t]{2}{*}{$2(28)$} & 2.51 & 2.76 & & & & & & & & & 2.51 \\
\hline & $(1.31)$ & $(1.1)$ & & & & & & & & & $(1.31)$ \\
\hline \multirow{2}{*}{$3(18)$} & 0.01 & 3.68 & 4.17 & & & & & & & & 1.89 \\
\hline & $(0)$ & $(1.26)$ & $(1.44)$ & & & & & & & & $(1.01)$ \\
\hline \multirow[t]{2}{*}{$5(11)$} & -1.45 & 2.06 & 6.18 & -3.00 & 9.39 & & & & & & 0.95 \\
\hline & $(-0.49)$ & $(0.85)$ & $(1.28)$ & $(-1.53)$ & $(2.55)$ & & & & & & $(0.57)$ \\
\hline \multirow[t]{2}{*}{$7(8)$} & -5.93 & 3.03 & 6.08 & 1.62 & 0.46 & -2.26 & 14.39 & & & & 0.64 \\
\hline & $(-2.17)$ & $(0.79)$ & (1.91) & $(0.3)$ & $(0.1)$ & $(-1.21)$ & $(3.98)$ & & & & $(0.41)$ \\
\hline \multirow[t]{2}{*}{$10(6)$} & -5.92 & 2.27 & 0.53 & 3.35 & 12.22 & 1.16 & -4.46 & -1.25 & 10.65 & 7.89 & 2.11 \\
\hline & $(-1.53)$ & $(0.55)$ & $(0.11)$ & $(1.4)$ & (3.15) & $(0.14)$ & $(-1.58)$ & $(-0.45)$ & $(1.59)$ & $(3.25)$ & $(1.25)$ \\
\hline
\end{tabular}


Table 3: Returns on the size portfolio based on a double sort on betas and size when I vary the number of BM quantiles to group the years with similar states: Mean and $(t-$ Mean $)$, the ratio of the mean return to its standard error, of the return on the SMB portfolio in 1963-2014.

I split each sample into (1), 2, 3, 5, 7, or 10 quantiles based on the $B M_{t}$ state variable and report the results for all of these groups of years. Each row corresponds to a given number of quantiles. The number of quantiles is in the first column: All years (i.e., the whole sample), 2, 3, 5, 7, or 10. The number of years in each group is in brackets. The next 10 columns contain the results for each respective group of years, from 1 to 10, depending on the number of quantiles considered. The last column, "Ex top", displays the results considering all the years except the ones in the highest BM quantile. The variable $B M_{t}$ is determined in July of year $t$, and all the returns are from July of year $t$ to the end of June in $t+1$.

\begin{tabular}{|c|c|c|c|c|c|c|c|c|c|c|c|}
\hline \multicolumn{12}{|c|}{ Return on the Size portfolio double sorted on size and betas in each state (BM quantile) } \\
\hline & Bottom & 2 & 3 & 4 & 5 & 6 & 7 & 8 & 9 & Top & Ex top \\
\hline \multicolumn{12}{|l|}{$1963-2014$} \\
\hline All (51 obs.) & $\begin{array}{r}3.23 \\
(2.21)\end{array}$ & & & & & & & & & & \\
\hline \multirow[t]{2}{*}{$2(26)$} & 1.64 & 4.76 & & & & & & & & & 1.64 \\
\hline & $(0.86)$ & $(2.17)$ & & & & & & & & & $(0.86)$ \\
\hline \multirow[t]{2}{*}{$3(17)$} & -1.50 & 6.62 & 4.57 & & & & & & & & 2.56 \\
\hline & $(-0.78)$ & $(2.49)$ & $(1.73)$ & & & & & & & & $(1.45)$ \\
\hline \multirow[t]{2}{*}{$5(10)$} & -2.69 & 4.83 & 4.96 & -2.65 & 10.78 & & & & & & 1.39 \\
\hline & $(-1.02)$ & $(1.42)$ & $(1.52)$ & $(-1.24)$ & $(3.71)$ & & & & & & (0.89) \\
\hline \multirow[t]{2}{*}{$7(7)$} & -6.18 & 3.23 & 7.70 & 1.94 & 0.61 & 3.98 & 11.08 & & & & 1.98 \\
\hline & $(-2.24)$ & (1.09) & $(2.1)$ & $(0.85)$ & $(0.12)$ & (1.06) & $(3.61)$ & & & & (1.28) \\
\hline \multirow[t]{2}{*}{$10(5)$} & -6.85 & 1.46 & 0.35 & 9.31 & 3.92 & 5.70 & -4.34 & -1.30 & 12.37 & 9.19 & 2.58 \\
\hline & $(-1.74)$ & $(0.55)$ & $(0.08)$ & (1.88) & $(1.21)$ & (1.08) & $(-0.94)$ & $(-0.83)$ & $(2.73)$ & $(2.29)$ & (1.67) \\
\hline
\end{tabular}


Table 4: Predictive regressions for 1 or 5 years for the excess return on the market, the market variance, and the derivative of the pseudo-conditional Sharpe ratio with respect to $B M_{t}$. I show the results in the full sample and in different states of the economy (BM terciles) in the periods 1926-2014, 1926-1960, and 1960-2014.

The row $R m$ displays the $B M_{t}$ coefficients, $\beta_{q}$, from Eq. (17): $R_{m, t \rightarrow t+q}=\alpha_{q}+\beta_{q} B M_{t}+\epsilon_{t \rightarrow t+q}$ followed by the respective adjusted coefficient of determination (in \%). The row $S V A R_{m}$ displays the $B M_{t}$ coefficients, $\beta_{q}$, from Eq. (18): $S V A R_{m, t \rightarrow t+q}=\alpha_{q}+\beta_{q} B M_{t}+\epsilon_{t \rightarrow t+q}$ followed by the respective adjusted coefficient of determination (in \%). The row $\frac{\partial S R}{\partial B M_{t}}$ displays the average of the partial derivatives of the pseudo-conditional Sharpe ratios in Eq. (20) with respect to $B M_{t}$. The t-statistics of the results are in brackets. The left panel reports the results for the future $q=1$ (year) values, and the right panel reports the results for the future $q=5$ (years) in the equations above. Each panel splits horizontally into four parts: All, Low BM, Med BM, and High BM states. "All" contains the results for the entire sample period. Low, Med, and High BM states correspond to the three states of the economy ( $B M_{t}$ terciles): In a given sample, the years in which $B M_{t}$ is in the lowest tercile across all the years are "Low", the ones in the highest tercile are "High", and the remaining ones are "Med".

\begin{tabular}{|c|c|c|c|c|c|c|c|c|}
\hline & \multicolumn{4}{|c|}{$q=1$ year } & \multicolumn{4}{|c|}{$\mathrm{q}=5$ years } \\
\hline & All & Low BM & Med BM & High BM & All & Low BM & Med BM & High BM \\
\hline $\begin{array}{l}1926-2014 \\
R_{m}\end{array}$ & $\begin{array}{l}19.90 \\
(3.02)\end{array}$ & $\begin{array}{l}24.13 \\
(0.83)\end{array}$ & $\begin{array}{l}15.27 \\
(0.61)\end{array}$ & $\begin{array}{c}35.92 \\
(1.74)\end{array}$ & $\begin{array}{l}66.16 \\
(4.27)\end{array}$ & $\begin{array}{l}158.51 \\
(1.87)\end{array}$ & $\begin{array}{r}75.95 \\
(1.24)\end{array}$ & $\begin{array}{c}79.98 \\
(1.81)\end{array}$ \\
\hline $\bar{R}^{2}$ & 8.5 & -1.1 & -2.2 & 6.5 & 0.2 & 0.1 & 0.0 & 0.1 \\
\hline$S V A R_{m}$ & $\begin{array}{c}0.04 \\
(3.13)\end{array}$ & $\begin{array}{l}-0.01 \\
(-0.17)\end{array}$ & $\begin{array}{l}-0.05 \\
(-1.13)\end{array}$ & $\begin{array}{c}0.15 \\
(4.87)\end{array}$ & $\begin{array}{l}0.07 \\
(1.4)\end{array}$ & $\begin{array}{c}-0.13 \\
(-0.43)\end{array}$ & $\begin{array}{c}0.23 \\
(1.03)\end{array}$ & $\begin{array}{c}0.23 \\
(1.96)\end{array}$ \\
\hline $\bar{R}^{2}$ & 9.2 & -3.7 & 0.9 & 43.9 & 0.0 & 0.0 & 0.0 & 0.1 \\
\hline$\frac{\partial S R}{\partial B M_{t}}$ & $\begin{array}{c}0.99 \\
(18.47)\end{array}$ & $\begin{array}{c}1.35 \\
(121.59)\end{array}$ & $\begin{array}{c}1.42 \\
(14.74)\end{array}$ & $\begin{array}{c}-0.63 \\
(-2.22)\end{array}$ & $\begin{array}{c}1.41 \\
(68.83)\end{array}$ & $\begin{array}{c}3.76 \\
(65.1)\end{array}$ & $\begin{array}{c}1.25 \\
(41.53)\end{array}$ & $\begin{array}{c}0.90 \\
(42.28)\end{array}$ \\
\hline $1926-1960$ & & & & & & & & \\
\hline$R_{m}$ & $\begin{array}{l}38.94 \\
(2.65)\end{array}$ & $\begin{array}{c}120.84 \\
(3.92)\end{array}$ & $\begin{array}{c}135.15 \\
(1.56)\end{array}$ & $\begin{array}{l}52.21 \\
(1.11)\end{array}$ & $\begin{array}{c}100.60 \\
(2.9)\end{array}$ & $\begin{array}{l}97.72 \\
(0.74)\end{array}$ & $\begin{array}{c}344.90 \\
(0.89)\end{array}$ & $\begin{array}{l}71.14 \\
(0.91)\end{array}$ \\
\hline $\bar{R}^{2}$ & 15.0 & 56.6 & 11.6 & 2.2 & 19.8 & -5.9 & -2.1 & -1.8 \\
\hline$S V A R_{m}$ & $\begin{array}{c}0.09 \\
(3.13)\end{array}$ & $\begin{array}{c}-0.21 \\
(-2.13)\end{array}$ & $\begin{array}{l}-0.06 \\
(-0.47)\end{array}$ & $\begin{array}{l}0.19 \\
(2.9)\end{array}$ & $\begin{array}{c}0.11 \\
(0.92)\end{array}$ & $\begin{array}{c}-0.34 \\
(-0.47)\end{array}$ & $\begin{array}{l}-1.33 \\
(-1.13)\end{array}$ & $\begin{array}{c}0.35 \\
(2.01)\end{array}$ \\
\hline $\bar{R}^{2}$ & 20.6 & 24.4 & -7.6 & 42.5 & -0.5 & -7.6 & 2.5 & 23.3 \\
\hline$\frac{\partial S R}{\partial B M_{t}}$ & $\begin{array}{c}2.57 \\
(3.92)\end{array}$ & $\begin{array}{c}172.26 \\
(1.11)\end{array}$ & $\begin{array}{c}10.03 \\
(17.58)\end{array}$ & $\begin{array}{c}0.93 \\
(12.72)\end{array}$ & $\begin{array}{c}1.82 \\
(43.45)\end{array}$ & $\begin{array}{c}2.27 \\
(18.03)\end{array}$ & $\begin{array}{l}21.08 \\
(3.31)\end{array}$ & $\begin{array}{c}-0.01 \\
(-0.16)\end{array}$ \\
\hline $\begin{array}{l}1960-2014 \\
R_{m}\end{array}$ & $\begin{array}{c}4.56 \\
(0.59)\end{array}$ & $\begin{array}{l}22.90 \\
(0.52)\end{array}$ & $\begin{array}{l}-83.98 \\
(-1.34)\end{array}$ & $\begin{array}{c}-3.51 \\
(-0.19)\end{array}$ & $\begin{array}{l}29.20 \\
(1.38)\end{array}$ & $\begin{array}{c}277.83 \\
(2.35)\end{array}$ & $\begin{array}{c}-358.88 \\
(-2.11)\end{array}$ & $\begin{array}{l}-46.99 \\
(-1.23)\end{array}$ \\
\hline $\bar{R}^{2}$ & -1.2 & -4.5 & 4.2 & -6.0 & 1.8 & 24.4 & 16.9 & 3.0 \\
\hline$S V A R_{m}$ & $\begin{array}{l}-0.02 \\
(-1.2)\end{array}$ & $\begin{array}{c}0.02 \\
(0.17)\end{array}$ & $\begin{array}{l}0.05 \\
(0.6)\end{array}$ & $\begin{array}{c}0.00 \\
(0.39)\end{array}$ & $\begin{array}{c}-0.12 \\
(-3.46)\end{array}$ & $\begin{array}{c}-0.54 \\
(-2.01)\end{array}$ & $\begin{array}{c}-0.02 \\
(-0.09)\end{array}$ & $\begin{array}{c}-0.04 \\
(-0.91)\end{array}$ \\
\hline $\bar{R}^{2}$ & 0.8 & -6.5 & -3.7 & -5.2 & 18.3 & 17.9 & -6.6 & -1.0 \\
\hline$\frac{\partial S R}{\partial B M_{t}}$ & $\begin{array}{c}0.45 \\
(18.8)\end{array}$ & $\begin{array}{c}1.14 \\
(76.28)\end{array}$ & $\begin{array}{c}-6.93 \\
(-24.18)\end{array}$ & $\begin{array}{c}-0.32 \\
(-77.13)\end{array}$ & $\begin{array}{c}1.52 \\
(6.16)\end{array}$ & $\begin{array}{c}7.03 \\
(16.16)\end{array}$ & $\begin{array}{c}-11.64 \\
(-410.8)\end{array}$ & $\begin{array}{l}-1.16 \\
(-44.7)\end{array}$ \\
\hline
\end{tabular}


Table 5: Predictive regressions for 1 or 5 years for the excess return on the market, the market variance, and the derivative of the pseudo-conditional Sharpe ratio with respect to $S M B_{t}^{*}$. I show the results in the full sample and in different states of the economy (BM terciles) in the periods 1926-2014, 1926-1960, and 1960-2014.

The row $R m$ displays the $S M B_{t}^{*}$ coefficients, $\beta_{q}$, from Eq. (17): $R_{m, t \rightarrow t+q}=\alpha_{q}+\beta_{q} S M B_{t}^{*}+\epsilon_{t \rightarrow t+q}$ followed by the respective adjusted coefficient of determination (in \%). The row $S V A R_{m}$ displays the $S M B_{t}^{*}$ coefficients, $\beta_{q}$, from Eq. (18): $S V A R_{m, t \rightarrow t+q}=\alpha_{q}+\beta_{q} S M B_{t}^{*}+\epsilon_{t \rightarrow t+q}$ followed by the respective adjusted coefficient of determination (in \%). The row $\frac{\partial S R}{\partial S M B_{t}^{*}}$ displays the average of the partial derivatives of the pseudo-conditional Sharpe ratios in Eq. (20) with respect to $S M B_{t}^{*}$. The t-statistics of the results are in brackets. The left panel reports the results for the future $q=1$ (year) values, and the right panel reports the results for the future $q=5$ (years) in the equations above. Each panel splits horizontally into four parts: All, Low BM, Med BM, and High BM states. "All" contains the results for the entire sample period. Low, Med, and High BM states correspond to the three states of the economy ( $B M_{t}$ terciles): In a given sample, the years in which $B M_{t}$ is in the lowest tercile across all the years are "Low", the ones in the highest tercile are "High", and the remaining ones are "Med".

\begin{tabular}{|c|c|c|c|c|c|c|c|c|}
\hline & \multicolumn{4}{|c|}{$q=1$ year } & \multicolumn{4}{|c|}{$\mathrm{q}=5$ years } \\
\hline $1926-2014$ & All & Low BM & Med BM & High BM & All & Low BM & Med BM & High BM \\
\hline$R_{m}$ & $\begin{array}{l}17.28 \\
(1.52)\end{array}$ & $\begin{array}{l}22.26 \\
(1.95)\end{array}$ & $\begin{array}{c}0.24 \\
(0.02)\end{array}$ & $\begin{array}{l}32.52 \\
(0.68)\end{array}$ & $\begin{array}{l}72.45 \\
(2.67)\end{array}$ & $\begin{array}{l}85.50 \\
(2.61)\end{array}$ & $\begin{array}{l}40.98 \\
(1.39)\end{array}$ & $\begin{array}{l}33.68 \\
(0.33)\end{array}$ \\
\hline $\bar{R}^{2}$ & 1.5 & 9.0 & -3.6 & -1.9 & 0.1 & 0.2 & 0.0 & 0.0 \\
\hline$S V A R_{m}$ & $\begin{array}{c}-0.03 \\
(-1.34)\end{array}$ & $\begin{array}{l}-0.05 \\
(-1.82)\end{array}$ & $\begin{array}{l}-0.01 \\
(-0.41)\end{array}$ & $\begin{array}{l}-0.03 \\
(-0.32)\end{array}$ & $\begin{array}{l}-0.18 \\
(-2.2)\end{array}$ & $\begin{array}{l}-0.16 \\
(-1.28)\end{array}$ & $\begin{array}{l}-0.10 \\
(-0.89)\end{array}$ & $\begin{array}{l}-0.49 \\
(-1.84)\end{array}$ \\
\hline $\bar{R}^{2}$ & 0.9 & 7.9 & -3.0 & -3.2 & 0.0 & 0.0 & 0.0 & 0.1 \\
\hline$\frac{\partial S R}{\partial S M B_{t}^{*}}$ & $\begin{array}{c}1.20 \\
(40.3)\end{array}$ & $\begin{array}{c}1.74 \\
(12.28)\end{array}$ & $\begin{array}{c}0.07 \\
(40.24)\end{array}$ & $\begin{array}{c}1.81 \\
(55.63)\end{array}$ & $\begin{array}{c}2.48 \\
(30.28)\end{array}$ & $\begin{array}{c}2.39 \\
(23.3)\end{array}$ & $\begin{array}{c}1.55 \\
(23.07)\end{array}$ & $\begin{array}{c}3.46 \\
(7.77)\end{array}$ \\
\hline $\begin{array}{l}1926-1960 \\
R_{m}\end{array}$ & $\begin{array}{c}71.41 \\
(1.88)\end{array}$ & $\begin{array}{l}42.72 \\
(1.34)\end{array}$ & $\begin{array}{l}103.71 \\
(2.77)\end{array}$ & $\begin{array}{l}63.77 \\
(0.32)\end{array}$ & $\begin{array}{c}251.94 \\
(3.05)\end{array}$ & $\begin{array}{l}172.43 \\
(2.51)\end{array}$ & $\begin{array}{c}201.69 \\
(1.01)\end{array}$ & $\begin{array}{c}251.74 \\
(0.79)\end{array}$ \\
\hline $\bar{R}^{2}$ & 6.9 & 6.8 & 37.8 & -9.9 & 21.6 & 39.8 & 0.1 & -3.9 \\
\hline$S V A R_{m}$ & $\begin{array}{l}-0.02 \\
(-0.29)\end{array}$ & $\begin{array}{l}-0.14 \\
(-1.95)\end{array}$ & $\begin{array}{l}-0.15 \\
(-2.9)\end{array}$ & $\begin{array}{c}0.30 \\
(0.86)\end{array}$ & $\begin{array}{c}-0.76 \\
(-2.95)\end{array}$ & $\begin{array}{l}-1.16 \\
(-3.3)\end{array}$ & $\begin{array}{l}-1.15 \\
(-2.15)\end{array}$ & $\begin{array}{c}0.03 \\
(0.04)\end{array}$ \\
\hline $\bar{R}^{2}$ & -2.8 & 20.3 & 40.2 & -2.7 & 18.5 & 47.3 & 24.8 & -11.1 \\
\hline$\frac{\partial S R}{\partial S M B_{t}^{*}}$ & $\begin{array}{c}3.40 \\
(92.08)\end{array}$ & $\begin{array}{c}4.05 \\
(3.91)\end{array}$ & $\begin{array}{l}28.24 \\
(2.24)\end{array}$ & $\begin{array}{c}0.44 \\
(2.16)\end{array}$ & $\begin{array}{c}9.52 \\
(9.83)\end{array}$ & $\begin{array}{l}15.57 \\
(1.9)\end{array}$ & $\begin{array}{l}23.61 \\
(2.62)\end{array}$ & $\begin{array}{c}4.67 \\
(308.06)\end{array}$ \\
\hline $\begin{array}{l}1960-2014 \\
R_{m}\end{array}$ & $\begin{array}{l}10.68 \\
(1.29)\end{array}$ & $\begin{array}{l}16.85 \\
(1.19)\end{array}$ & $\begin{array}{c}21.82 \\
(1.6)\end{array}$ & $\begin{array}{l}-35.79 \\
(-1.44)\end{array}$ & $\begin{array}{l}53.95 \\
(2.48)\end{array}$ & $\begin{array}{l}45.99 \\
(1.07)\end{array}$ & $\begin{array}{l}75.60 \\
(1.98)\end{array}$ & $\begin{array}{l}-24.89 \\
(-0.45)\end{array}$ \\
\hline $\bar{R}^{2}$ & 1.2 & 2.4 & 8.0 & 5.9 & 9.3 & 1.0 & 14.7 & -4.9 \\
\hline$S V A R_{m}$ & $\begin{array}{l}-0.02 \\
(-1.29)\end{array}$ & $\begin{array}{c}-0.04 \\
(-0.95)\end{array}$ & $\begin{array}{c}0.00 \\
(0.06)\end{array}$ & $\begin{array}{l}-0.02 \\
(-1.61)\end{array}$ & $\begin{array}{c}-0.01 \\
(-0.27)\end{array}$ & $\begin{array}{c}0.06 \\
(0.58)\end{array}$ & $\begin{array}{c}-0.05 \\
(-1.27)\end{array}$ & $\begin{array}{c}0.11 \\
(1.68)\end{array}$ \\
\hline $\bar{R}^{2}$ & 1.2 & -0.7 & -5.9 & 8.5 & -1.9 & -5.0 & 3.6 & 9.6 \\
\hline$\frac{\partial S R}{\partial S M B_{t}^{*}}$ & $\begin{array}{c}0.87 \\
(34.02)\end{array}$ & $\begin{array}{c}1.06 \\
(15.83)\end{array}$ & $\begin{array}{c}1.54 \\
(269.23)\end{array}$ & $\begin{array}{c}-2.28 \\
(-18.23)\end{array}$ & $\begin{array}{c}1.53 \\
(328.47)\end{array}$ & $\begin{array}{c}0.98 \\
(53.42)\end{array}$ & $\begin{array}{c}2.89 \\
(28.84)\end{array}$ & $\begin{array}{c}-1.51 \\
(-19.49)\end{array}$ \\
\hline
\end{tabular}


Table 6: Predictive regressions for 1 or 5 years for the excess return on the market, the market variance, and the derivative of the pseudo-conditional Sharpe ratio with respect to $S M B_{t}^{*}$. I show the results in the full sample and for different values of $S M B^{*}$ (in terciles) in the periods 1926-2014, 1926-1960, and 1960-2014.

The row $R m$ displays the $S M B_{t}^{*}$ coefficients, $\beta_{q}$, from Eq. (17): $R_{m, t \rightarrow t+q}=\alpha_{q}+\beta_{q} S M B_{t}^{*}+\epsilon_{t \rightarrow t+q}$ followed by the respective adjusted coefficient of determination (in \%). The row $S V A R_{m}$ displays the $S M B_{t}^{*}$ coefficients, $\beta_{q}$, from Eq. (18): $S V A R_{m, t \rightarrow t+q}=\alpha_{q}+\beta_{q} S M B_{t}^{*}+\epsilon_{t \rightarrow t+q}$ followed by the respective adjusted coefficient of determination (in \%). The row $\frac{\partial S R}{\partial S M B_{t}^{*}}$ displays the average of the partial derivatives of the pseudo-conditional Sharpe ratios in Eq. (20) with respect to $S M B_{t}^{*}$. The t-statistics of the results are in brackets. The left panel reports the results for the future $q=1$ (year) values, and the right panel reports the results for the future $q=5$ (years) in the equations above. Each panel splits horizontally into four parts: All, Low SMB*, Med SMB*, and High SMB*. "All" contains the results for the entire sample period. Low, Med, and High SMB* correspond to the three $S M B_{t}^{*}$ terciles: In a given sample, the years in which $S M B_{t}^{*}$ is in the lowest tercile across all the years are "Low", the ones in the highest tercile are "High", and the remaining ones are "Med".

\begin{tabular}{|c|c|c|c|c|c|c|c|c|}
\hline & \multicolumn{4}{|c|}{$q=1$ year } & \multicolumn{4}{|c|}{$\mathrm{q}=5$ years } \\
\hline & All & Low SMB* & Med SMB* & High SMB* & All & Low SMB* & Med SMB* & High SMB* \\
\hline $\begin{array}{l}1926-2014 \\
R_{m}\end{array}$ & $\begin{array}{l}17.28 \\
(1.52)\end{array}$ & $\begin{array}{l}44.07 \\
(2.38)\end{array}$ & $\begin{array}{c}145.34 \\
(1.54)\end{array}$ & $\begin{array}{c}-100.17 \\
(-2.01)\end{array}$ & $\begin{array}{l}72.45 \\
(2.67)\end{array}$ & $\begin{array}{l}124.91 \\
(3.55)\end{array}$ & $\begin{array}{c}-199.32 \\
(-0.77)\end{array}$ & $\begin{array}{c}-155.50 \\
(-1.31)\end{array}$ \\
\hline $\bar{R}^{2}$ & 1.5 & 13.9 & 4.5 & 9.8 & 0.1 & 0.3 & 0.0 & 0.0 \\
\hline$S V A R_{m}$ & $\begin{array}{c}-0.03 \\
(-1.34)\end{array}$ & $\begin{array}{l}-0.06 \\
(-1.91)\end{array}$ & $\begin{array}{l}-0.38 \\
(-1.7)\end{array}$ & $\begin{array}{l}-0.14 \\
(-1.45)\end{array}$ & $\begin{array}{l}-0.18 \\
(-2.2)\end{array}$ & $\begin{array}{l}-0.36 \\
(-1.69)\end{array}$ & $\begin{array}{l}-0.45 \\
(-0.65)\end{array}$ & $\begin{array}{l}-0.14 \\
(-0.66)\end{array}$ \\
\hline $\bar{R}^{2}$ & 0.9 & 8.4 & 6.1 & 3.9 & 0.0 & 0.1 & 0.0 & 0.0 \\
\hline$\frac{\partial S R}{\partial S M B_{t}^{*}}$ & $\begin{array}{c}1.20 \\
(40.3)\end{array}$ & $\begin{array}{c}2.85 \\
(19.05)\end{array}$ & $\begin{array}{l}15.49 \\
(7.43)\end{array}$ & $\begin{array}{l}-6.20 \\
(-3.74)\end{array}$ & $\begin{array}{c}2.48 \\
(30.28)\end{array}$ & $\begin{array}{c}3.36 \\
(19.34)\end{array}$ & $\begin{array}{c}-2.67 \\
(-79.78)\end{array}$ & $\begin{array}{c}-3.34 \\
(-49.63)\end{array}$ \\
\hline $\begin{array}{l}1926-1960 \\
R_{m}\end{array}$ & $\begin{array}{l}71.41 \\
(1.88)\end{array}$ & $\begin{array}{l}64.40 \\
(1.42)\end{array}$ & $\begin{array}{l}-24.94 \\
(-0.09)\end{array}$ & $\begin{array}{l}58.40 \\
(0.14)\end{array}$ & $\begin{array}{c}251.94 \\
(3.05)\end{array}$ & $\begin{array}{c}180.83 \\
(2.4)\end{array}$ & $\begin{array}{l}-82.71 \\
(-0.18)\end{array}$ & $\begin{array}{c}517.82 \\
(0.54)\end{array}$ \\
\hline $\bar{R}^{2}$ & 6.9 & 8.4 & -9.9 & -10.9 & 21.6 & 34.6 & -10.7 & -8.5 \\
\hline$S V A R_{m}$ & $\begin{array}{c}-0.02 \\
(-0.29)\end{array}$ & $\begin{array}{l}-0.16 \\
(-1.74)\end{array}$ & $\begin{array}{c}0.31 \\
(0.45)\end{array}$ & $\begin{array}{c}1.04 \\
(1.46)\end{array}$ & $\begin{array}{l}-0.76 \\
(-2.95)\end{array}$ & $\begin{array}{l}-1.41 \\
(-2.78)\end{array}$ & $\begin{array}{c}0.52 \\
(0.25)\end{array}$ & $\begin{array}{c}0.99 \\
(0.59)\end{array}$ \\
\hline $\bar{R}^{2}$ & -2.8 & 15.6 & -7.9 & 10.1 & 18.5 & 37.9 & -9.3 & -7.0 \\
\hline$\frac{\partial S R}{\partial S M B_{t}^{*}}$ & $\begin{array}{c}3.40 \\
(92.08)\end{array}$ & $\begin{array}{c}3.85 \\
(9.52)\end{array}$ & $\begin{array}{c}-2.22 \\
(-10.69)\end{array}$ & $\begin{array}{l}-21.67 \\
(-3.6)\end{array}$ & $\begin{array}{c}9.52 \\
(9.83)\end{array}$ & $\begin{array}{c}4.21 \\
(7.46)\end{array}$ & $\begin{array}{c}-8.04 \\
(-22.09)\end{array}$ & $\begin{array}{c}7.49 \\
(30.88)\end{array}$ \\
\hline $\begin{array}{l}1960-2014 \\
R_{m}\end{array}$ & $\begin{array}{l}10.68 \\
(1.29)\end{array}$ & $\begin{array}{l}24.38 \\
(1.21)\end{array}$ & $\begin{array}{c}9.76 \\
(0.21)\end{array}$ & $\begin{array}{l}-92.72 \\
(-2.15)\end{array}$ & $\begin{array}{l}53.95 \\
(2.48)\end{array}$ & $\begin{array}{l}69.55 \\
(2.06)\end{array}$ & $\begin{array}{c}79.91 \\
(0.3)\end{array}$ & $\begin{array}{c}0.24 \\
(0)\end{array}$ \\
\hline $\bar{R}^{2}$ & 1.2 & 2.6 & -6.0 & 17.5 & 9.3 & 15.2 & -6.5 & -7.1 \\
\hline$S V A R_{m}$ & $\begin{array}{c}-0.02 \\
(-1.29)\end{array}$ & $\begin{array}{c}0.00 \\
(0.07)\end{array}$ & $\begin{array}{c}-0.02 \\
(-0.27)\end{array}$ & $\begin{array}{l}-0.06 \\
(-0.98)\end{array}$ & $\begin{array}{c}-0.01 \\
(-0.27)\end{array}$ & $\begin{array}{l}-0.10 \\
(-1.22)\end{array}$ & $\begin{array}{l}-0.35 \\
(-0.94)\end{array}$ & $\begin{array}{l}-0.19 \\
(-0.89)\end{array}$ \\
\hline $\bar{R}^{2}$ & 1.2 & -5.9 & -5.8 & -0.2 & -1.9 & 2.7 & -0.7 & -1.5 \\
\hline$\frac{\partial S R}{\partial S M B_{t}^{*}}$ & $\begin{array}{c}0.87 \\
(34.02)\end{array}$ & $\begin{array}{c}1.29 \\
(207.32)\end{array}$ & $\begin{array}{c}1.03 \\
(70.01)\end{array}$ & $\begin{array}{l}-5.92 \\
(-9.28)\end{array}$ & $\begin{array}{c}1.53 \\
(328.47)\end{array}$ & $\begin{array}{c}2.15 \\
(27.75)\end{array}$ & $\begin{array}{c}5.10 \\
(15.73)\end{array}$ & $\begin{array}{c}0.61 \\
(16.35)\end{array}$ \\
\hline
\end{tabular}


Table 7: The 1-year returns on the SMB portfolio compared with the ICAPM predictions, considering the validity of $B M_{t}$ as a state variable and its properties.

For each sample 1926-2014, 1926-1960, and 1960-2014 I report $\overline{S M B}$, the average return on the SMB portfolio; cov $(S M B, \Delta B M)$, the covariance between the return on the SMB portfolio and the 1-year changes in $B M_{t} ; \operatorname{cov}\left(M P_{1 y}, B M\right)$ and $\operatorname{cov}\left(M P_{5}\right.$, $\left.B M\right)$, respectively the covariance between the future 1- or 5 -years returns on the market and $B M_{t} ; \operatorname{cov}\left(\operatorname{svar}_{1 y}, B M\right)$ and $\operatorname{cov}\left(\operatorname{svar}_{5}, B M\right)$, respectively the covariance between the future 1- or 5-years realized variance of the market returns and $B M_{t}$; and $d S R_{1 y}$ and $d S R_{5 y}$, respectively the average of the derivative of the future 1- or 5-years market Sharpe ratio with respect to $B M_{t}$. The respective t-statistics are in brackets. Next to each covariance there is a plus sign (+) when the return on the SMB portfolio has a positive covariance with the investment opportunities according to that particular metric (regardless of any significance). The panel splits horizontally into four parts: All, Low BM, Med BM, and High BM states. "All" contains the results for the entire sample period. Low, Med, and High BM states correspond to the three states of the economy ( $B M_{t}$ terciles): In a given sample, the years in which $B M_{t}$ is in the lowest tercile across all the years are "Low", the ones in the highest tercile are "High", and the remaining ones are "Med".

\begin{tabular}{|c|c|c|c|c|c|c|c|c|}
\hline \multirow{2}{*}{$1926-2014$} & \multicolumn{2}{|c|}{ All } & \multicolumn{2}{|c|}{ Low BM } & \multicolumn{2}{|c|}{ Med BM } & \multicolumn{2}{|c|}{ High BM } \\
\hline & & & & & & & & \\
\hline \multirow{2}{*}{$\overline{S M B}$} & & 2.78 & & 1.18 & & -1.29 & & 8.39 \\
\hline & & $(2.15)$ & & $(0.59)$ & & $(-0.65)$ & & $(3.56)$ \\
\hline \multirow[t]{2}{*}{$\operatorname{cov}(S M B, \Delta B M)$} & -0.47 & & -0.59 & & -0.65 & & 0.10 & \\
\hline & $(1.51)$ & & $(1.59)$ & & $(1.36)$ & & $(0.14)$ & \\
\hline \multirow[t]{2}{*}{$\operatorname{cov}\left(M P_{1 y}, B M\right)$} & 3.13 & & 0.38 & & 0.22 & & 3.47 & + \\
\hline & $(3.02)$ & & $(0.83)$ & & $(0.61)$ & & $(1.74)$ & \\
\hline \multirow{2}{*}{$\operatorname{cov}\left(M P_{5 y}, B M\right)$} & 10.34 & & 2.44 & & 1.08 & & 7.73 & + \\
\hline & $(4.27)$ & & (1.87) & & $(1.24)$ & & $(1.81)$ & \\
\hline \multirow{2}{*}{$\operatorname{cov}\left(\operatorname{svar}_{1 y}, B M\right)$} & 0.63 & + & -0.02 & & -0.07 & & 1.42 & \\
\hline & (3.13) & & $(0.17)$ & & $(1.13)$ & & $(4.87)$ & \\
\hline \multirow[t]{2}{*}{$\operatorname{cov}\left(\operatorname{svar}_{5 y}, B M\right)$} & 1.09 & + & -0.20 & & 0.33 & + & 2.27 & \\
\hline & $(1.4)$ & & $(0.43)$ & & $(1.03)$ & & $(1.96)$ & \\
\hline \multirow[t]{2}{*}{$d S R_{1 y}$} & 98.72 & & 134.78 & & 142.50 & & -62.65 & \\
\hline & $(18.47)$ & & $(121.59)$ & & $(14.74)$ & & $(-2.22)$ & \\
\hline \multirow[t]{2}{*}{$d S R_{5 y}$} & 141.07 & & 376.32 & & 125.26 & & 89.52 & + \\
\hline & $(68.83)$ & & $(65.1)$ & & $(41.53)$ & & $(42.28)$ & \\
\hline \multicolumn{9}{|l|}{ 1926-1960 } \\
\hline \multirow[t]{2}{*}{$\overline{S M B}$} & & 2.95 & & -2.16 & & 0.99 & & 10.65 \\
\hline & & $(1.34)$ & & $(-0.67)$ & & $(0.46)$ & & $(2.14)$ \\
\hline \multirow[t]{2}{*}{$\operatorname{cov}(S M B, \Delta B M)$} & -0.92 & & -1.98 & & -0.83 & & 1.25 & \\
\hline & $(1.3)$ & & $(1.82)$ & & $(1.75)$ & & $(0.63)$ & \\
\hline \multirow[t]{2}{*}{$\operatorname{cov}\left(M P_{1 y}, B M\right)$} & 5.50 & & 2.07 & & 0.48 & & 7.07 & + \\
\hline & $(2.65)$ & & $(3.92)$ & & $(1.56)$ & & $(1.11)$ & \\
\hline \multirow[t]{2}{*}{$\operatorname{cov}\left(M P_{5 y}, B M\right)$} & 14.61 & & 2.09 & & 1.31 & & 9.63 & + \\
\hline & $(2.9)$ & & $(0.74)$ & & $(0.89)$ & & $(0.91)$ & \\
\hline \multirow[t]{2}{*}{$\operatorname{cov}\left(\operatorname{svar}_{1 y}, B M\right)$} & 1.21 & + & -0.36 & & -0.02 & & 2.55 & \\
\hline & $(3.13)$ & & $(2.13)$ & & $(0.47)$ & & $(2.9)$ & \\
\hline $\operatorname{cov}\left(\operatorname{svar}_{5 y}, B M\right)$ & 1.50 & + & -0.57 & & -0.48 & & 4.70 & \\
\hline & $(0.92)$ & & $(0.47)$ & & $(1.13)$ & & $(2.01)$ & \\
\hline$d S R_{1 y}$ & 256.72 & & 17225.59 & & 1002.85 & & 92.98 & + \\
\hline & $(3.92)$ & & $(1.11)$ & & $(17.58)$ & & $(12.72)$ & \\
\hline$d S R_{5 y}$ & 182.24 & & 226.88 & & 2108.28 & & -1.08 & \\
\hline & $(43.45)$ & & $(18.03)$ & & $(3.31)$ & & $(-0.16)$ & \\
\hline $1960-2014$ & & & & & & & & \\
\hline$\overline{S M B}$ & & 2.64 & & 0.01 & & 3.68 & & 4.17 \\
\hline & & $(1.68)$ & & $(0)$ & & $(1.26)$ & & $(1.44)$ \\
\hline $\operatorname{cov}(S M B, \Delta B M)$ & -0.20 & & 0.23 & & -0.88 & & 0.39 & \\
\hline & $(0.67)$ & & $(0.53)$ & & $(1.64)$ & & $(0.73)$ & \\
\hline $\operatorname{cov}\left(M P_{1 y}, B M\right)$ & 0.40 & & 0.20 & & -0.32 & + & -0.19 & \\
\hline & $(0.59)$ & & $(0.52)$ & & $(1.34)$ & & $(0.19)$ & \\
\hline $\operatorname{cov}\left(M P_{5 y}, B M\right)$ & 2.62 & & 2.23 & & -1.45 & + & -2.54 & \\
\hline & $(1.38)$ & & $(2.35)$ & & $(2.11)$ & & $(1.23)$ & \\
\hline $\operatorname{cov}\left(\operatorname{svar}_{1 y}, B M\right)$ & -0.15 & & 0.02 & + & 0.02 & + & 0.02 & \\
\hline & $(1.2)$ & & $(0.17)$ & & $(0.6)$ & & $(0.39)$ & \\
\hline $\operatorname{cov}\left(\operatorname{svar}_{5 y}, B M\right)$ & -1.08 & & -0.43 & & -0.01 & & -0.24 & + \\
\hline & $(3.46)$ & & $(2.01)$ & & $(0.09)$ & & $(0.91)$ & \\
\hline$d S R_{1 y}$ & 45.16 & & 113.71 & & -693.18 & + & -31.54 & \\
\hline & $(18.8)$ & & $(76.28)$ & & $(-24.18)$ & & $(-77.13)$ & \\
\hline$d S R_{5 y}$ & 152.23 & & 703.29 & & -1163.92 & + & -115.56 & \\
\hline & $(6.16)$ & & $(16.16)$ & & $(-410.8)$ & & $(-44.7)$ & \\
\hline
\end{tabular}


Table 8: The 1-year returns on the SMB portfolio compared with the ICAPM predictions, considering the validity of $S M B^{*}$ as a state variable and its properties but conditioning on the BM state of the economy.

For each sample 1926-2014, 1926-1960, and 1960-2014 I report $\overline{S M B}$, the average return on the SMB portfolio; cov $\left(S M B, \Delta S M B B^{*}\right)$, the covariance between the return on the SMB portfolio and the 1-year changes in $S M B^{*} ; \operatorname{cov}\left(M P_{1 y}, S M B^{*}\right)$ and $\operatorname{cov}\left(M P_{5 y}, S M B^{*}\right)$, respectively the covariance between the future 1- or 5-years returns on the market and $S M B^{*} ; \operatorname{cov}\left(\operatorname{svar}_{1 y}, S M B^{*}\right)$ and $\operatorname{cov}\left(\operatorname{svar} 5 y, S M B^{*}\right)$, respectively the covariance between the future 1 - or 5 -years realized variance of the market returns and $S M B^{*}$; and $d S R_{1 y}$ and $d S R_{5}$, respectively the average of the derivative of the future 1- or 5-years market Sharpe ratio with respect to $S M B^{*}$. The respective t-statistics are in brackets. Next to each covariance there is a plus sign (+) when the return on the SMB portfolio has a positive covariance with the investment opportunities according to that particular metric (regardless of any significance). The panel splits horizontally into four parts: All, Low BM, Med BM, and High BM states. "All" contains the results for the entire sample period. Low, Med, and High BM states correspond to the three states of the economy ( $B M_{t}$ terciles): In a given sample, the years in which $B M_{t}$ is in the lowest tercile across all the years are "Low", the ones in the highest tercile are "High", and the remaining ones are "Med".

\begin{tabular}{|c|c|c|c|c|c|c|c|c|}
\hline & \multicolumn{2}{|c|}{ All } & \multicolumn{2}{|c|}{ Low BM } & \multicolumn{2}{|c|}{ Med BM } & \multicolumn{2}{|c|}{ High BM } \\
\hline & & & & & & & & \\
\hline$\overline{S M B}$ & & $\begin{array}{c}2.78 \\
(2.15)\end{array}$ & & $\begin{array}{c}1.18 \\
(0.59)\end{array}$ & & $\begin{array}{l}-1.29 \\
(-0.65)\end{array}$ & & $\begin{array}{c}8.39 \\
(3.56)\end{array}$ \\
\hline $\operatorname{cov}\left(S M B, \Delta S M B^{*}\right)$ & $\begin{array}{c}0.85 \\
(3.43)\end{array}$ & & $\begin{array}{l}0.87 \\
(1.8)\end{array}$ & & $\begin{array}{c}0.91 \\
(2.34)\end{array}$ & & $\begin{array}{c}0.58 \\
(1.71)\end{array}$ & \\
\hline $\operatorname{cov}\left(M P_{1 y}, S M B^{*}\right)$ & $\begin{array}{c}0.99 \\
(\mathbf{1 . 5 2})\end{array}$ & + & $\begin{array}{l}2.02 \\
(\mathbf{1 . 9 5})\end{array}$ & + & $\begin{array}{c}0.01 \\
(\mathbf{0 . 0 2})\end{array}$ & + & $\begin{array}{c}0.64 \\
\mathbf{( 0 . 6 8 )}\end{array}$ & + \\
\hline $\operatorname{cov}\left(M P_{5 y}, S M B^{*}\right)$ & $\begin{array}{l}4.16 \\
(\mathbf{2 . 6 7})\end{array}$ & + & $\begin{array}{l}7.82 \\
(\mathbf{2 . 6 1 )}\end{array}$ & + & $\begin{array}{c}2.45 \\
(\mathbf{1 . 3 9})\end{array}$ & + & $\begin{array}{c}0.66 \\
(\mathbf{0 . 3 3})\end{array}$ & + \\
\hline $\operatorname{cov}\left(\operatorname{svar}_{1 y}, S M B^{*}\right)$ & $\begin{array}{l}-0.17 \\
(\mathbf{1 . 3 4})\end{array}$ & + & $\begin{array}{l}-0.43 \\
(\mathbf{1 . 8 2})\end{array}$ & + & $\begin{array}{l}-0.06 \\
(\mathbf{0 . 4 1 )}\end{array}$ & + & $\begin{array}{l}-0.06 \\
\mathbf{( 0 . 3 2 )}\end{array}$ & + \\
\hline $\operatorname{cov}\left(\operatorname{svar}_{5 y}, S M B^{*}\right)$ & $\begin{array}{l}-1.02 \\
(\mathbf{2 . 2})\end{array}$ & + & $\begin{array}{l}-1.39 \\
(\mathbf{1 . 2 8})\end{array}$ & + & $\begin{array}{l}-0.60 \\
(\mathbf{0 . 8 9})\end{array}$ & + & $\begin{array}{l}-0.97 \\
(\mathbf{1 . 8 4})\end{array}$ & + \\
\hline$d S R_{1 y}$ & $\begin{array}{l}119.77 \\
(40.3)\end{array}$ & + & $\begin{array}{l}174.31 \\
(12.28)\end{array}$ & + & $\begin{array}{c}7.27 \\
(40.24)\end{array}$ & + & $\begin{array}{l}180.51 \\
(55.63)\end{array}$ & + \\
\hline$d S R_{5 y}$ & $\begin{array}{l}248.00 \\
(30.28)\end{array}$ & + & $\begin{array}{l}239.49 \\
(23.3)\end{array}$ & + & $\begin{array}{l}154.70 \\
(23.07)\end{array}$ & + & $\begin{array}{l}346.24 \\
(7.77)\end{array}$ & + \\
\hline \multicolumn{9}{|l|}{$1926-1960$} \\
\hline$\overline{S M B}$ & & $\begin{array}{c}2.95 \\
(1.34)\end{array}$ & & $\begin{array}{l}-2.16 \\
(-0.67)\end{array}$ & & $\begin{array}{c}0.99 \\
(0.46)\end{array}$ & & $\begin{array}{l}10.65 \\
(2.14)\end{array}$ \\
\hline $\operatorname{cov}\left(S M B, \Delta S M B^{*}\right)$ & $\begin{array}{c}0.15 \\
(0.39)\end{array}$ & & $\begin{array}{c}0.28 \\
(0.33)\end{array}$ & & $\begin{array}{l}-0.17 \\
(0.52)\end{array}$ & & $\begin{array}{c}0.91 \\
(1.65)\end{array}$ & \\
\hline $\operatorname{cov}\left(M P_{1 y}, S M B^{*}\right)$ & $\begin{array}{c}1.65 \\
(\mathbf{1 . 8 8})\end{array}$ & + & $\begin{array}{c}1.47 \\
(\mathbf{1 . 3 4})\end{array}$ & + & $\begin{array}{l}1.40 \\
(\mathbf{2 . 7 7})\end{array}$ & + & $\begin{array}{c}0.53 \\
(\mathbf{0 . 3 2})\end{array}$ & + \\
\hline $\operatorname{cov}\left(M P_{5 y}, S M B^{*}\right)$ & $\begin{array}{c}6.29 \\
(\mathbf{3 . 0 5})\end{array}$ & + & $\begin{array}{l}7.68 \\
(\mathbf{2 . 5 1 )}\end{array}$ & + & $\begin{array}{c}2.78 \\
(\mathbf{1 . 0 1})\end{array}$ & + & $\begin{array}{l}2.10 \\
(\mathbf{0 . 7 9})\end{array}$ & + \\
\hline $\operatorname{cov}\left(\operatorname{svar}_{1 y}, S M B^{*}\right)$ & $\begin{array}{l}-0.05 \\
(\mathbf{0 . 2 9})\end{array}$ & + & $\begin{array}{l}-0.48 \\
(\mathbf{1 . 9 5})\end{array}$ & + & $\begin{array}{l}-0.20 \\
(\mathbf{2 . 9})\end{array}$ & + & $\begin{array}{l}0.25 \\
(\mathbf{0 . 8 6})\end{array}$ & \\
\hline $\operatorname{cov}\left(\operatorname{svar}_{5 y}, S M B^{*}\right)$ & $\begin{array}{l}-1.75 \\
(\mathbf{2 . 9 5})\end{array}$ & + & $\begin{array}{l}-3.99 \\
\mathbf{( 3 . 3 )}\end{array}$ & + & $\begin{array}{l}-1.55 \\
(\mathbf{2 . 1 5})\end{array}$ & + & $\begin{array}{c}0.03 \\
(\mathbf{0 . 0 4})\end{array}$ & \\
\hline$d S R_{1 y}$ & $\begin{array}{l}339.85 \\
(92.08)\end{array}$ & + & $\begin{array}{l}404.99 \\
(3.91)\end{array}$ & + & $\begin{array}{c}2823.60 \\
(2.24)\end{array}$ & + & $\begin{array}{l}44.23 \\
(2.16)\end{array}$ & + \\
\hline$d S R_{5 y}$ & $\begin{array}{l}951.73 \\
(9.83)\end{array}$ & + & $\begin{array}{c}1556.77 \\
(1.9)\end{array}$ & + & $\begin{array}{c}2361.18 \\
(2.62)\end{array}$ & + & $\begin{array}{c}466.91 \\
(308.06)\end{array}$ & + \\
\hline \multicolumn{9}{|l|}{$1960-2014$} \\
\hline$\overline{S M B}$ & & $\begin{array}{c}2.64 \\
(1.68)\end{array}$ & & $\begin{array}{c}0.01 \\
(0)\end{array}$ & & $\begin{array}{c}3.68 \\
(1.26)\end{array}$ & & $\begin{array}{c}4.17 \\
(1.44)\end{array}$ \\
\hline $\operatorname{cov}\left(S M B, \Delta S M B^{*}\right)$ & $\begin{array}{c}1.30 \\
(4.15)\end{array}$ & & $\begin{array}{l}1.25 \\
(2.79)\end{array}$ & & $\begin{array}{c}0.59 \\
(0.91)\end{array}$ & & $\begin{array}{c}1.92 \\
(4.66)\end{array}$ & \\
\hline $\operatorname{cov}\left(M P_{1 y}, S M B^{*}\right)$ & $\begin{array}{c}0.81 \\
(\mathbf{1 . 2 9})\end{array}$ & + & $\begin{array}{l}1.35 \\
(\mathbf{1 . 1 9})\end{array}$ & + & $\begin{array}{l}1.71 \\
\mathbf{( 1 . 6 )}\end{array}$ & + & $\begin{array}{l}-0.97 \\
\mathbf{( 1 . 4 4 )}\end{array}$ & \\
\hline $\operatorname{cov}\left(M P_{5 y}, S M B^{*}\right)$ & $\begin{array}{c}4.23 \\
(\mathbf{2 . 4 8})\end{array}$ & + & $\begin{array}{c}3.65 \\
(\mathbf{1 . 0 7})\end{array}$ & + & $\begin{array}{c}6.23 \\
\mathbf{( 1 . 9 8 )}\end{array}$ & + & $\begin{array}{l}-0.68 \\
\mathbf{( 0 . 4 5 )}\end{array}$ & \\
\hline $\operatorname{cov}\left(\operatorname{svar}_{1 y}, S M B^{*}\right)$ & $\begin{array}{l}-0.15 \\
(\mathbf{1 . 2 9})\end{array}$ & + & $\begin{array}{l}-0.32 \\
(\mathbf{0 . 9 5})\end{array}$ & + & $\begin{array}{c}0.01 \\
\mathbf{( 0 . 0 6 )}\end{array}$ & & $\begin{array}{l}-0.07 \\
\mathbf{( 1 . 6 1 )}\end{array}$ & + \\
\hline $\operatorname{cov}\left(\operatorname{svar}_{5 y}, S M B^{*}\right)$ & $\begin{array}{l}-0.09 \\
(\mathbf{0 . 2 7})\end{array}$ & + & $\begin{array}{c}0.44 \\
\mathbf{( 0 . 5 8 )}\end{array}$ & & $\begin{array}{l}-0.40 \\
(\mathbf{1 . 2 7})\end{array}$ & + & $\begin{array}{c}0.29 \\
\mathbf{( 1 . 6 8 )}\end{array}$ & \\
\hline$d S R_{1 y}$ & $\begin{array}{c}87.01 \\
(34.02)\end{array}$ & + & $\begin{array}{l}105.98 \\
(15.83)\end{array}$ & + & $\begin{array}{c}153.69 \\
(269.23)\end{array}$ & + & $\begin{array}{l}-227.99 \\
(-18.23)\end{array}$ & \\
\hline$d S R_{5 y}$ & $\begin{array}{c}153.16 \\
(328.47)\end{array}$ & + & $\begin{array}{c}97.72 \\
(53.42)\end{array}$ & + & $\begin{array}{l}289.22 \\
(28.84)\end{array}$ & + & $\begin{array}{l}-151.18 \\
(-19.49)\end{array}$ & \\
\hline
\end{tabular}


Table 9: The 1-year returns on the SMB portfolio compared with the ICAPM predictions, considering the validity of $S M B^{*}$ as a state variable and its properties.

For each sample 1926-2014, 1926-1960, and 1960-2014 I report $\overline{S M B}$, the average return on the SMB portfolio; cov( $S M B, \Delta S M B *)$, the covariance between the return on the SMB portfolio and the 1-year changes in $S M B^{*} ; \operatorname{cov}\left(M P_{1 y}, S M B^{*}\right)$ and $\operatorname{cov}\left(M P_{5 y}, S M B^{*}\right)$, respectively the covariance between the future 1 - or 5 -years returns on the market and $S M B^{*} ; \operatorname{cov}\left(\operatorname{svar} 1 y, S M B^{*}\right)$ and $\operatorname{cov}\left(\operatorname{svar} 5 y, S M B^{*}\right)$, respectively the covariance between the future 1- or 5-years realized variance of the market returns and $S M B^{*}$; and $d S R_{1 y}$ and $d S R_{5 y}$, respectively the average of the derivative of the future 1- or 5-years market's Sharpe ratio with respect to $S M B^{*}$. 'The respective t-statistics are in brackets. Next to each covariance there is a plus sign $(+)$ when the return on the SMB portfolio has a positive covariance with the investment opportunities according to that particular metric (regardless of any significance). The panel splits horizontally into four parts: All, Low SMB*, Med SMB*, and High SMB*. "All" contains the results for the entire sample period. Low, Med, and High SMB* correspond to the three $S M B_{t}^{*}$ terciles: In a given sample, the years in which $S M B_{t}^{*}$ is in the lowest tercile across all the years are "Low", the ones in the highest tercile are "High", and the remaining ones are "Med".

\begin{tabular}{|c|c|c|c|c|c|c|c|c|}
\hline & \multicolumn{2}{|c|}{ All } & \multicolumn{2}{|c|}{ Low SMB* } & \multicolumn{2}{|c|}{ Med SMB* } & \multicolumn{2}{|c|}{ High SMB* } \\
\hline \multicolumn{9}{|l|}{$1926-2014$} \\
\hline$\overline{S M B}$ & & $\begin{array}{c}2.78 \\
(2.15)\end{array}$ & & $\begin{array}{c}-0.26 \\
(-0.13)\end{array}$ & & $\begin{array}{c}4.36 \\
(2.48)\end{array}$ & & $\begin{array}{c}4.29 \\
(1.57)\end{array}$ \\
\hline $\operatorname{cov}\left(S M B, \Delta S M B^{*}\right)$ & $\begin{array}{c}0.85 \\
(3.43)\end{array}$ & & $\begin{array}{c}0.88 \\
(1.79)\end{array}$ & & $\begin{array}{c}0.62 \\
(2.59)\end{array}$ & & $\begin{array}{c}1.42 \\
(3.14)\end{array}$ & \\
\hline $\operatorname{cov}\left(M P_{1 y}, S M B^{*}\right)$ & $\begin{array}{c}0.99 \\
\mathbf{( 1 . 5 2 )}\end{array}$ & + & $\begin{array}{c}1.72 \\
(\mathbf{2 . 3 8})\end{array}$ & + & $\begin{array}{c}0.28 \\
\mathbf{( 1 . 5 4 )}\end{array}$ & + & $\begin{array}{l}-1.31 \\
(\mathbf{2 . 0 1})\end{array}$ & \\
\hline $\operatorname{cov}\left(M P_{5 y}, S M B^{*}\right)$ & $\begin{array}{c}4.16 \\
(\mathbf{2 . 6 7})\end{array}$ & + & $\begin{array}{c}4.89 \\
(\mathbf{3 . 5 5})\end{array}$ & + & $\begin{array}{l}-0.40 \\
(\mathbf{0 . 7 7})\end{array}$ & & $\begin{array}{l}-2.07 \\
(\mathbf{1 . 3 1})\end{array}$ & \\
\hline $\operatorname{cov}\left(\operatorname{svar}_{1 y}, S M B^{*}\right)$ & $\begin{array}{l}-0.17 \\
\mathbf{( 1 . 3 4 )}\end{array}$ & + & $\begin{array}{l}-0.24 \\
(\mathbf{1 . 9 1 )}\end{array}$ & + & $\begin{array}{c}-0.07 \\
(\mathbf{1 . 7})\end{array}$ & + & $\begin{array}{l}-0.19 \\
(\mathbf{1 . 4 5})\end{array}$ & + \\
\hline $\operatorname{cov}\left(\operatorname{svar}_{5 y}, S M B^{*}\right)$ & $\begin{array}{l}-1.02 \\
(\mathbf{2 . 2})\end{array}$ & + & $\begin{array}{l}-1.39 \\
(\mathbf{1 . 6 9})\end{array}$ & + & $\begin{array}{l}-0.09 \\
(\mathbf{0 . 6 5})\end{array}$ & + & $\begin{array}{l}-0.20 \\
(\mathbf{0 . 6 6 )}\end{array}$ & + \\
\hline$d S R_{1 y}$ & $\begin{array}{l}119.77 \\
(40.3)\end{array}$ & + & $\begin{array}{l}284.89 \\
(19.05)\end{array}$ & + & $\begin{array}{c}1549.24 \\
(7.43)\end{array}$ & + & $\begin{array}{c}-620.31 \\
(-3.74)\end{array}$ & \\
\hline$d S R_{5 y}$ & $\begin{array}{c}248.00 \\
(30.28)\end{array}$ & + & $\begin{array}{c}336.41 \\
(19.34)\end{array}$ & + & $\begin{array}{l}-267.24 \\
(-79.78)\end{array}$ & & $\begin{array}{l}-334.23 \\
(-49.63)\end{array}$ & \\
\hline \multicolumn{9}{|l|}{$1926-1960$} \\
\hline$\overline{S M B}$ & & $\begin{array}{c}2.95 \\
(1.34)\end{array}$ & & $\begin{array}{l}-0.95 \\
(-0.3)\end{array}$ & & $\begin{array}{c}0.50 \\
(0.33)\end{array}$ & & $\begin{array}{l}9.86 \\
(1.8)\end{array}$ \\
\hline $\operatorname{cov}\left(S M B, \Delta S M B^{*}\right)$ & $\begin{array}{c}0.15 \\
(0.39)\end{array}$ & & $\begin{array}{c}0.02 \\
(0.03)\end{array}$ & & $\begin{array}{c}0.04 \\
(0.28)\end{array}$ & & $\begin{array}{c}1.37 \\
(3.64)\end{array}$ & \\
\hline $\operatorname{cov}\left(M P_{1 y}, S M B^{*}\right)$ & $\begin{array}{c}1.65 \\
\mathbf{( 1 . 8 8 )}\end{array}$ & + & $\begin{array}{c}1.39 \\
(\mathbf{1 . 4 2})\end{array}$ & + & $\begin{array}{l}-0.02 \\
(\mathbf{0 . 0 9})\end{array}$ & & $\begin{array}{c}0.08 \\
(\mathbf{0 . 1 4})\end{array}$ & + \\
\hline $\operatorname{cov}\left(M P_{5 y}, S M B^{*}\right)$ & $\begin{array}{c}6.29 \\
(\mathbf{3 . 0 5})\end{array}$ & + & $\begin{array}{l}4.37 \\
(\mathbf{2 . 4})\end{array}$ & + & $\begin{array}{l}-0.08 \\
(\mathbf{0 . 1 8})\end{array}$ & & $\begin{array}{c}0.74 \\
(\mathbf{0 . 5 4})\end{array}$ & + \\
\hline $\operatorname{cov}\left(\operatorname{svar}_{1 y}, S M B^{*}\right)$ & $\begin{array}{l}-0.05 \\
(\mathbf{0 . 2 9})\end{array}$ & + & $\begin{array}{l}-0.35 \\
(\mathbf{1 . 7 4})\end{array}$ & + & $\begin{array}{c}0.03 \\
(\mathbf{0 . 4 5})\end{array}$ & & $\begin{array}{c}0.14 \\
\mathbf{( 1 . 4 6 )}\end{array}$ & \\
\hline $\operatorname{cov}\left(\operatorname{svar}_{5 y}, S M B^{*}\right)$ & $\begin{array}{l}-1.75 \\
(\mathbf{2 . 9 5})\end{array}$ & + & $\begin{array}{l}-3.06 \\
(\mathbf{2 . 7 8})\end{array}$ & + & $\begin{array}{c}0.05 \\
(\mathbf{0 . 2 5})\end{array}$ & & $\begin{array}{c}0.13 \\
(\mathbf{0 . 5 9})\end{array}$ & \\
\hline$d S R_{1 y}$ & $\begin{array}{l}339.85 \\
(92.08)\end{array}$ & + & $\begin{array}{c}385.00 \\
(9.52)\end{array}$ & + & $\begin{array}{l}-222.08 \\
(-10.69)\end{array}$ & & $\begin{array}{c}-2167.30 \\
(-3.6)\end{array}$ & \\
\hline$d S R_{5 y}$ & $\begin{array}{c}951.73 \\
(9.83)\end{array}$ & + & $\begin{array}{l}421.33 \\
(7.46)\end{array}$ & + & $\begin{array}{l}-804.21 \\
(-22.09)\end{array}$ & & $\begin{array}{r}749.09 \\
(30.88)\end{array}$ & + \\
\hline \multicolumn{9}{|l|}{$1960-2014$} \\
\hline$\overline{S M B}$ & & $\begin{array}{c}2.64 \\
(1.68)\end{array}$ & & $\begin{array}{c}2.92 \\
(0.95)\end{array}$ & & $\begin{array}{c}2.30 \\
(0.94)\end{array}$ & & $\begin{array}{c}2.68 \\
(0.99)\end{array}$ \\
\hline $\operatorname{cov}\left(S M B, \Delta S M B^{*}\right)$ & $\begin{array}{c}1.30 \\
(4.15)\end{array}$ & & $\begin{array}{c}1.45 \\
(2.06)\end{array}$ & & $\begin{array}{c}0.98 \\
(2.72)\end{array}$ & & $\begin{array}{c}1.59 \\
(3.19)\end{array}$ & \\
\hline $\operatorname{cov}\left(M P_{1 y}, S M B^{*}\right)$ & $\begin{array}{c}0.81 \\
(\mathbf{1 . 2 9})\end{array}$ & + & $\begin{array}{c}1.24 \\
(\mathbf{1 . 2 1})\end{array}$ & + & $\begin{array}{c}0.03 \\
(\mathbf{0 . 2 1})\end{array}$ & + & $\begin{array}{l}-0.91 \\
(\mathbf{2 . 1 5})\end{array}$ & \\
\hline $\operatorname{cov}\left(M P_{5 y}, S M B^{*}\right)$ & $\begin{array}{c}4.23 \\
(\mathbf{2 . 4 8})\end{array}$ & + & $\begin{array}{c}3.53 \\
(\mathbf{2 . 0 6})\end{array}$ & + & $\begin{array}{l}0.24 \\
(\mathbf{0 . 3})\end{array}$ & + & $\begin{array}{r}0.00 \\
(\mathbf{0})\end{array}$ & + \\
\hline $\operatorname{cov}\left(\operatorname{svar}_{1 y}, S M B^{*}\right)$ & $\begin{array}{l}-0.15 \\
(\mathbf{1 . 2 9})\end{array}$ & + & $\begin{array}{c}0.02 \\
(\mathbf{0 . 0 7})\end{array}$ & & $\begin{array}{c}0.00 \\
(\mathbf{0 . 2 7})\end{array}$ & + & $\begin{array}{l}-0.06 \\
(\mathbf{0 . 9 8})\end{array}$ & + \\
\hline $\operatorname{cov}\left(\operatorname{svar}_{5 y}, S M B^{*}\right)$ & $\begin{array}{l}-0.09 \\
(\mathbf{0 . 2 7})\end{array}$ & + & $\begin{array}{l}-0.49 \\
(\mathbf{1 . 2 2})\end{array}$ & + & $\begin{array}{l}-0.10 \\
(\mathbf{0 . 9 4})\end{array}$ & + & $\begin{array}{l}-0.21 \\
(\mathbf{0 . 8 9})\end{array}$ & + \\
\hline$d S R_{1 y}$ & $\begin{array}{c}87.01 \\
(34.02)\end{array}$ & + & $\begin{array}{c}129.16 \\
(207.32)\end{array}$ & + & $\begin{array}{l}102.60 \\
(70.01)\end{array}$ & + & $\begin{array}{c}-591.58 \\
(-9.28)\end{array}$ & \\
\hline$d S R_{5 y}$ & $\begin{array}{c}153.16 \\
(328.47)\end{array}$ & + & $\begin{array}{l}214.62 \\
(27.75)\end{array}$ & + & $\begin{array}{c}509.71 \\
(15.73)\end{array}$ & + & $\begin{array}{c}61.14 \\
(16.35)\end{array}$ & + \\
\hline
\end{tabular}

